\title{
Cargo Recognition in Clathrin-Mediated Endocytosis
}

\author{
Linton M. Traub ${ }^{1}$ and Juan S. Bonifacino ${ }^{2}$ \\ ${ }^{1}$ Department of Cell Biology, University of Pittsburgh School of Medicine, Pittsburgh, Pennsylvania 15261 \\ ${ }^{2}$ Cell Biology and Metabolism Program, Eunice Kennedy Shriver National Institute of Child Health \\ and Human Development, National Institutes of Health, Bethesda, Maryland 20892 \\ Correspondence: traub@pitt.edu
}

The endosomal system is expansive and complex, characterized by swift morphological transitions, dynamic remodeling of membrane constituents, and intracellular positioning changes. To properly navigate this ever-altering membrane labyrinth, transmembrane protein cargoes typically require specific sorting signals that are decoded by components of protein coats. The best-characterized sorting process within the endosomal system is the rapid internalization of select transmembrane proteins within clathrin-coated vesicles. Endocytic signals consist of linear motifs, conformational determinants, or covalent modifications in the cytosolic domains of transmembrane cargo. These signals are interpreted by a diverse set of clathrin-associated sorting proteins (CLASPs) that translocate from the cytosol to the inner face of the plasma membrane. Signal recognition by CLASPs is highly cooperative, involving additional interactions with phospholipids, Arf GTPases, other CLASPs, and clathrin, and is regulated by large conformational changes and covalent modifications. Related sorting events occur at other endosomal sorting stations.

$T_{m}^{\text {he }}$ he internalization of a subset of plasma membrane proteins by clathrin-mediated endocytosis is one the best-characterized sorting processes that takes place in the endomembrane system of eukaryotic cells (Kirchhausen 2014). Selection of transmembrane proteins (referred to as "cargo") for internalization by clathrin-mediated endocytosis involves recognition of endocytic signals in the cytosolic domains of the proteins by adaptors located in the inner layer of clathrin coats. Signal-adaptor interactions lead to concentration of the transmembrane proteins within clathrin-coated pits that eventually bud into the cytoplasm as clathrin-coated vesicles (Kirchhausen 2014). Transmembrane proteins that have endocytic signals are thus rapidly delivered to endosomes, whereas those that lack signals remain at the plasma membrane. This article summarizes recent progress in the elucidation of the mechanisms of signal recognition in clathrin-mediated endocytosis, with additional reference to related intracellular sorting events. Further information on this topic can be found in previous reviews (Bonifacino and Traub 2003; Traub 2009; Kelly and Owen 2011).

Editors: Sandra L. Schmid, Alexander Sorkin, and Marino Zerial

Additional Perspectives on Endocytosis available at www.cshperspectives.org

Copyright (C) 2013 Cold Spring Harbor Laboratory Press; all rights reserved; doi: 10.1101/cshperspect.a016790

Cite this article as Cold Spring Harb Perspect Biol 2013;5:a016790 
L.M. Traub and J.S. Bonifacino

\section{DIVERSITY OF ENDOCYTIC SIGNALS}

The notion that endocytic receptors possess internalization signals was initially derived from morphologic, biochemical, and genetic studies of lipoprotein receptors, well before there was any knowledge of receptor structure (Brown and Goldstein 1979). With the advent of gene cloning, the amino acid sequences of various endocytic receptors became known in steady succession. Initial sequence comparisons, however, did not reveal any conserved groups of amino acids that could constitute a common endocytic signal. The identification of endocytic signals would end up requiring extensive molecular dissection of the receptor sequences using a combination of mutational and functional analyses. This effort led to the current understanding of endocytic signals as a highly diverse set of structural features in the cytosolic domains of transmembrane proteins, which can be grouped into three functionally analogous but structurally distinct classes: (1) linear motifs, (2) conformational determinants, and (3) covalent modifications.

Linear motifs are short arrays of invariant and variant amino acids, including "tyrosinebased" YXXØ (Collawn et al. 1990; Jadot et al. 1992) and [FY]XNPX[YF] motifs (Chen et al. 1990; Collawn et al. 1991), and "dileucinebased" [DE]XXXL[LI] motifs (Table 1) (Letourneur and Klausner 1992; Pond et al. 1995). In this notation, amino acids are represented in single-letter code, $\mathrm{X}$ indicates any amino acid, $\varnothing$ indicates an amino acid with a bulky hydrophobic side chain, and the brackets mean that either amino acid is allowed at that position. The invariant amino acids are the most critical elements, although the variant amino acids influence the strength and fine specificity of the

Table 1. Endocytic signals and adaptors

\begin{tabular}{|c|c|c|c|}
\hline Signals or domains & Adaptors & $\begin{array}{c}\text { Adaptor subunits } \\
\text { or domains }\end{array}$ & References \\
\hline YXXØ & AP-2 & $\mu 2$ & $\begin{array}{l}\text { Collawn et al. 1990; Jadot et al. 1992; Ohno } \\
\text { et al. 1995; Owen and Evans } 1998\end{array}$ \\
\hline$[\mathrm{DE}] \mathrm{XXXL}[\mathrm{LI}]$ & $\mathrm{AP}-2$ & $\alpha-\sigma 2$ & $\begin{array}{l}\text { Letourneur and Klausner 1992; Pond et al. } \\
\text { 1995; Chaudhuri et al. 2007; Doray et al. } \\
\text { 2007; Kelly et al. } 2008\end{array}$ \\
\hline Acidic clusters & $\mathrm{AP}-2 ?$ & $\alpha ?$ & Voorhees et al. 1995; Lindwasser et al. 2008 \\
\hline$[\mathrm{YF}] \mathrm{XNPX}[\mathrm{YF}]$ & $\begin{array}{l}\text { ARH; Dab2; Idol; } \\
\text { SNX17, 27, } \\
\text { and } 31\end{array}$ & PTB domain & $\begin{array}{l}\text { Chen et al. 1990; Collawn et al. 1991; He et al. } \\
\text { 2002; Mishra et al. 2002; Stockinger et al. } \\
\text { 2002; Zelcer et al. 2009; Ghai et al. } 2013\end{array}$ \\
\hline $\operatorname{NPFX}_{(1,2)} \mathrm{D}$ & Sla1p & $\begin{array}{l}\text { SLA1 homology } \\
\text { domain }\end{array}$ & Tan et al. 1996; Howard et al. 2002 \\
\hline Ubiquitin & $\begin{array}{l}\text { Eps15, Epsins } 1 \\
\quad \text { and } 2\end{array}$ & UIM domain & Polo et al. 2002; Shih et al. 2002 \\
\hline GPCR phosphorylation & $\beta$-arrestins 1 and 2 & Amino terminus & Ferguson et al. 1996; Goodman et al. 1996 \\
\hline $\begin{array}{l}\text { Synaptotagmin I C2A } \\
\text { (C2B) domain }\end{array}$ & Stonin 2 & $\mu \mathrm{HD}$ domain & Martina et al. 2001; Walther et al. 2001 \\
\hline Mid2p cytosolic domain & Syp $1 p$ & $\mu \mathrm{HD}$ domain & Reider et al. 2009 \\
\hline Alk8 cytosolic domain & Fcho1 & $\mu \mathrm{HD}$ domain & Umasankar et al. 2012 \\
\hline VAMP 7 longin domain & Hrb, AP-3 & $\begin{array}{l}\text { Carboxy- } \\
\text { terminal } \\
\text { unstructured } \\
\text { domain }\end{array}$ & Pryor et al. 2008; Kent et al. 2012 \\
\hline $\begin{array}{l}\text { VAMP 2, VAMP 3, VAMP } \\
8 \text { SNARE motifs }\end{array}$ & CALM & ANTH domain & Miller et al. 2011 \\
\hline
\end{tabular}

ARH, autosomal recessive hypercholesterolemia; PTB, phosphotyrosine-binding; UIM, ubiquitin-interacting motifs; GPCR, G-protein-coupled receptor; CALM, clathrin assembly lymphoid myeloid leukemia. 
signals. The function of the signals can also be affected by flanking sequences (Ohno et al. 1998), phosphorylation of amino acids at or near the motif (Shiratori et al. 1997; Pitcher et al. 1999), their spacing from the transmembrane domain (Rohrer et al. 1996), and palmitoylation of nearby cysteine residues (Schweizer et al. 1996). Linear motifs that function as signals are generally found within unstructured regions of the cytosolic domains.

Not all signals, however, are linear sequences or fit a canonical motif. There are now many examples of folded domains that contain information for endocytosis (Table 1) (Pryor et al. 2008; Yu et al. 2010; Miller et al. 2011). This information consists of conformational arrays of amino acids on the surface of the folded domains. Unlike linear motifs, which are common to many proteins, each conformational array described to date appears to be unique for a specific cargo. Finally, covalent modifications such as phosphorylation of hydroxyl amino acids (Ferguson et al. 1996; Di Fiore and von Zastrow 2014) or polyubiquitination on the $\varepsilon$-amino group of lysine residues (Hicke and Riezman 1996; Piper et al. 2014) in the cytosolic domains can also function as endocytic signals (Table 1). In these cases, the modifying groups do not modulate the activity of underlying linear or conformational signals, but themselves act as recognition determinants. Multiple or overlapping signals can occur within the same cytosolic domain (for example, see Johnson and Kornfeld 1992; Doray et al. 2008; Goh et al. 2010; Prabhu et al. 2012). Similar types of signal participate in sorting events that take place at intracellular compartments, such as the transGolgi network (TGN) and endosomes.

\section{MULTIPLICITY OF ADAPTORS}

The recognition of such a wide diversity of endocytic and intracellular sorting signals obviously necessitates the existence of multiple adaptors. Indeed, many proteins located in the inner layer of protein coats-including proteins that were initially categorized as "accessory"are now known to function as sorting adaptors (Fig. 1; Table 1). Depending on the identity of the scaffolding protein that forms the outer layer, coats are classified as clathrin coats or nonclathrin coats. Coats involved in rapid internalization from the plasma membrane contain clathrin as their main constituent and a set of adaptors known as "clathrin-associated sorting proteins" (CLASPs) (Fig. 1A). Clathrin coats containing different sets of CLASPs, as well as nonclathrin coats, mediate intracellular sorting events. CLASPs are recruited to membranes primarily via interactions with specific phosphoinositide lipids, small GTPases of the Arf family, and/or other CLASPs. Clathrin then binds to the CLASP armature and polymerizes into an overlying polyhedral scaffold. Concomitantly, CLASPs engage sorting signals in the cytosolic domains of transmembrane cargo, leading to cargo capture and stabilization of the coats. Both CLASP-clathrin (Dell'Angelica et al. 1998; Drake and Traub 2001) and CLASPCLASP interactions (Brett et al. 2002) involve linear motifs (analogous to, but distinct from, cargo sorting signals) binding to folded domains, highlighting the general role of this binding mode in the assembly and function of clathrin coats. Most interactions among components of clathrin coats are of moderate to low affinity (typically in the $1-100 \mu \mathrm{M}$ range), making this mechanism of sorting a highly cooperative and dynamic process.

From a structural standpoint, CLASPs can be categorized as (1) oligomeric (tetrameric or dimeric), and (2) monomeric (Fig. 1B). The main endocytic adaptor is the clathrin-associated, heterotetrameric adaptor protein 2 (AP-2) complex. This complex is composed of two large "adaptin" subunits ( $\alpha$ and $\beta 2$ ), one medium-sized subunit $(\mu 2)$, and one small subunit $(\sigma 2)$. AP-2 is a member of a family of homologous complexes that also includes AP-1 $(\gamma-\beta 1-\mu 1-\sigma 1)$, AP-3 $(\delta-\beta 3-\mu 3-\sigma 3)$, AP-4 ( $\varepsilon-$ $\beta 4-\mu 4-\sigma 4)$, AP-5 $(\zeta-\beta 5-\mu 5-\sigma 5)$, and COPI-F $(\gamma-\mathrm{COP}-\beta-\mathrm{COP}-\delta-\mathrm{COP}-\zeta-\mathrm{COP})$ (corresponding subunit composition in parentheses) (Robinson 2004; Hirst et al. 2011). All of these complexes are components of clathrin or nonclathrin coats that mediate sorting in intracellular compartments. They comprise a large globular "core" consisting of the amino-termi- 
L.M. Traub and J.S. Bonifacino

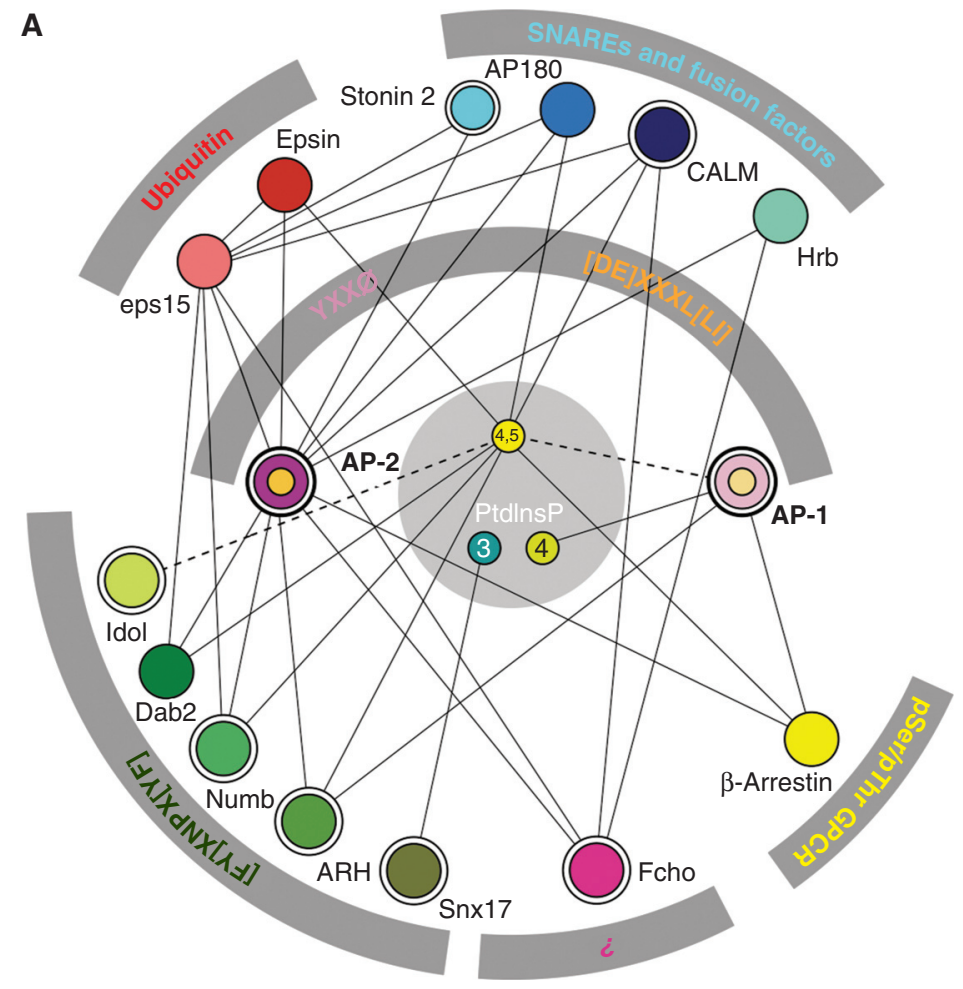

B

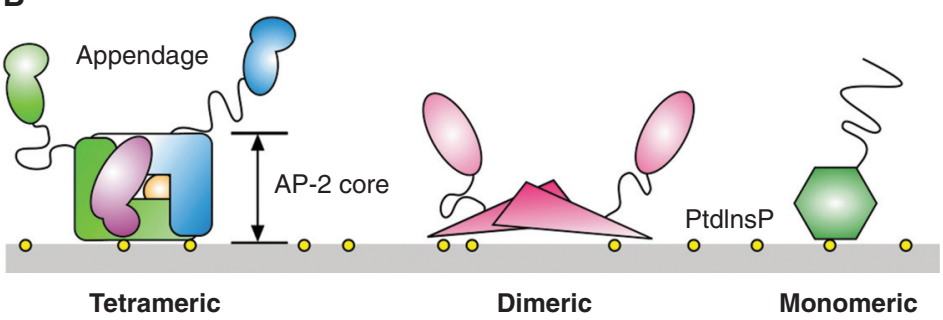

Figure 1. The endocytic cargo-adaptor interaction network. (A) Schematic representation of selected sorting signal-recognition partner relationships for endocytic trafficking. Both protein-protein and protein-lipid (PtdInsP) interactions among the cargo-selective machinery are highlighted with connection lines. The solid lines indicate documented physical interactions, whereas dashed lines connote either interactions possible based on properties of other domain relatives (IDOL) or known (AP-1), but still of unclear functional necessity. Adaptors, CLASPs, and regulators (Idol) discussed explicitly are double circled. (B) Representative modular domain architecture classes of selected endocytic proteins. Heterotetrameric examples are AP-1, AP-2, and AP3; dimeric examples are Fcho1, Syp1p, and eps15; and monomeric CLASPs include ARH, Dab2, Numb, CALM, AP180, epsin, and $\beta$-arrestin. Tertiary-structured domains are indicated by geometric shapes, and intrinsically disordered protein segments by a line.

nal "trunk" domains of the large subunits plus the entire medium and small subunits. The carboxy-terminal portions of the large subunits extend from the core as two long projections, each comprising a long disordered "hinge" sequence and a globular "ear" or "appendage" domain. The core mediates recruitment to membranes and sorting-signal recognition, whereas the hinge-appendage extensions interact with clathrin, other adaptors, and various accessory 
Cargo Recognition in Clathrin-Mediated Endocytosis

proteins. Dimeric and monomeric CLASPs and related adaptors consist of a single polypeptide chain in which the same functions are distributed among several globular domains joined by disordered linkers, giving them a "beads-on-astring" appearance.

\section{RECOGNITION OF LINEAR MOTIFS BY AP-2}

AP-2 recognizes YXX $\varnothing$ and [DE]XXXL[LI] signals through binding to two distinct sites on the core domain. The binding site for YXXØ motifs is located on the carboxy-terminal domain of $\mu 2$ ( $\mu 2-C)$ (Ohno et al. 1995), an immunoglobulin-like $\beta$-sandwich fold having hydrophobic pockets for the $\mathrm{Y}$ and $\varnothing$ residues (Fig. 2A) (Owen and Evans 1998). The Y pocket cannot accommodate phosphotyrosine, explaining why tyrosine phosphorylation prevents binding of YXXØ motifs to $\mu 2$ (Boll et al. 1996; Ohno et al. 1996) and endocytosis (Shiratori et al. 1997). The $\mu 2-\mathrm{C}$ domain has also been shown to bind the folded DEP domain of the signaling adaptor Disheveled at a surface near the YXXØ-binding site (Yu et al. 2010). The $[\mathrm{DE}] \mathrm{XXXL}[\mathrm{LI}]$-binding site is on the $\alpha-\sigma 2$ hemicomplex (Chaudhuri et al. 2007; Doray et al. 2007), with the acidic residue of the motif interacting with basic residues on both $\alpha$ and $\sigma 2$, and the two hydrophobic residues fitting into adjacent hydrophobic pockets on $\sigma 2$ (Fig. 2B) (Kelly et al. 2008; Mattera et al. 2011). A phosphoserine residue at position -5 from the first leucine (considered position 0 ) substitutes for the acidic residue at position -4 in the noncanonical dileucine signal from CD4, exemplifying how phosphorylation can also positively regulate AP-2 recognition and endocytosis (Fig. 2D) (Pitcher et al. 1999; Kelly et al. 2008).

Strikingly, the AP-2 core occurs in two distinct conformations: a "locked" conformation in which the binding sites for both YXXØ and [DE]XXXL[LI] signals are occluded by regions of $\beta 2$ (Collins et al. 2002), and an "open" conformation in which both sites are accessible (Fig. 3A) (Jackson et al. 2010). The change from the locked to the open conformation involves translocation of the $\mu 2-\mathrm{C}$ domain to an orthogonal face and displacement of the amino terminus of $\beta 2$ from the $\alpha-\sigma 2$ interface. In the open conformation, the YXXØ- and [DE]XXXL[LI]-binding sites are coplanar with four electropositive patches that bind phosphatidylinositol 4,5-bisphosphate $\left(\operatorname{Ptd} \operatorname{Ins}(4,5) \mathrm{P}_{2}\right)$ (Jackson et al. 2010), a phosphoinositide that is highly enriched in the plasma membrane (Di Paolo and De Camilli 2006). This coplanarity ensures coupling of signal recognition to membrane recruitment (Jackson et al. 2010). On the basis of these observations, it has been proposed that the AP-2 core exists in equilibrium between two conformers: the locked form that predominates in the cytosol and the open form that is mainly associated with membranes. The generation of PtdIns $(4,5) \mathrm{P}_{2}$ and availability of signal-bearing cargo at the plasma membrane shift the equilibrium toward the open form. AP-2 phosphorylation events also appear to contribute to the shift. For example, phosphorylation of a threonine residue (Thr156) in the linker that connects the amino- and carboxy-terminal domains of $\mu 2$ by the adaptor-associated kinase 1 (AAK1) enhances binding of AP-2 to endocytic signals and promotes receptor internalization (Olusanya et al. 2001; Conner and Schmid 2002; Ricotta et al. 2002). The $\mu 2$ linker is disordered in the locked form but folds into a fourturn $\alpha$ helix that binds to $\beta 2$ in the open form (Jackson et al. 2010). Thr156 phosphorylation could thus cause stabilization of this $\mu 2-$ $\beta 2$ interaction and, by extension, favor the open conformation of the core. In addition, $\beta 2$ residue Tyr6 undergoes phosphorylation on activation of the epidermal growth factor (EGF) receptor kinase (Huang et al. 2003). In the locked form of the AP- 2 core, $\beta 2$ Tyr6 occupies the $\sigma 2$ hydrophobic pocket for the [LI] residue in [DE]XXXL[LI] motifs (Kelly et al. 2008). Phosphorylation of this residue could unblock the dileucine-binding site, also favoring conversion to the open form of the AP-2 core. Because internalization of the activated EGF receptor is partly dependent on a dileucine-based signal (Huang et al. 2003), this phosphorylation event illustrates how a signaling receptor can promote its own endocytosis through activation of AP-2. 


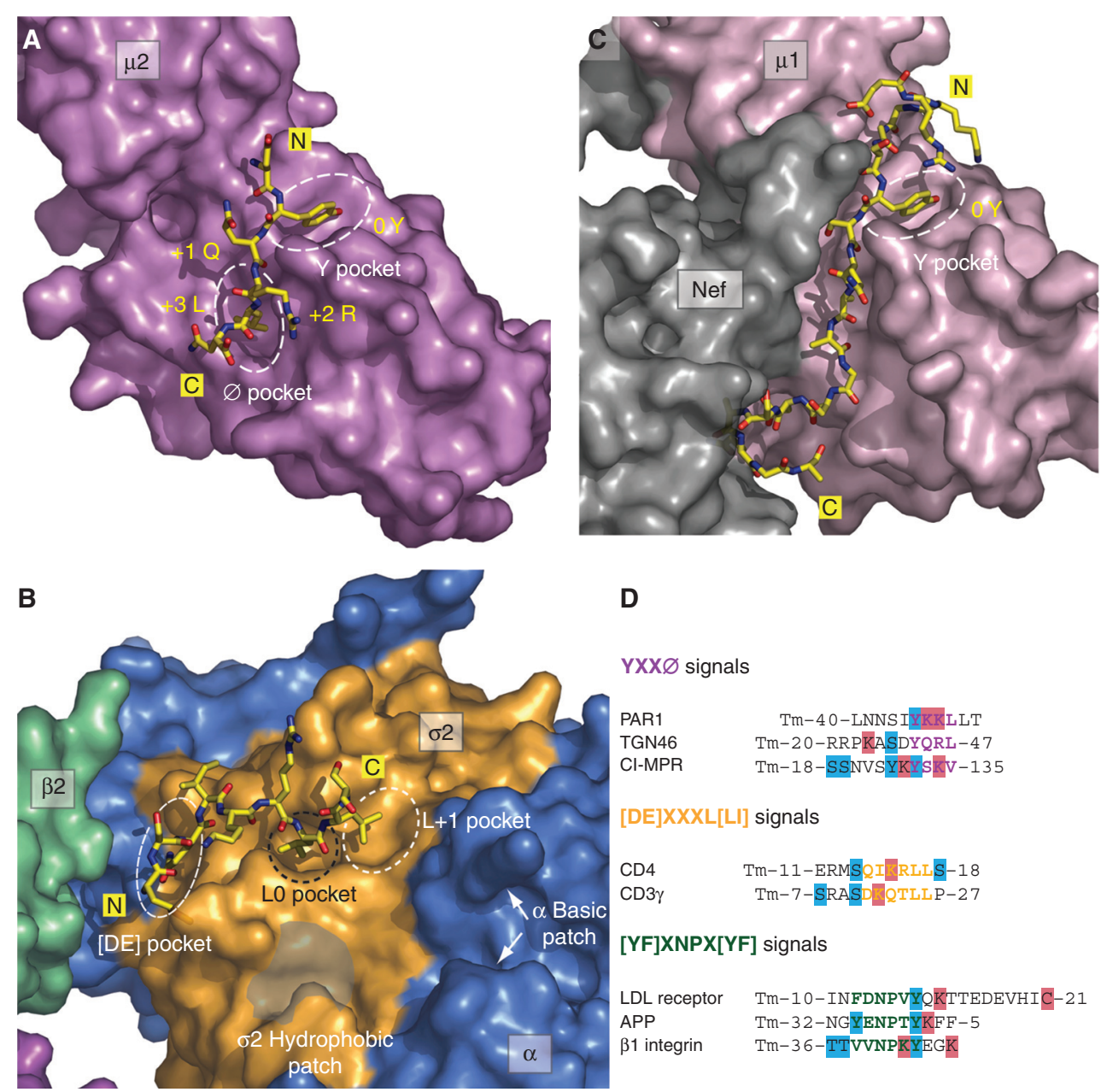

Figure 2. AP-1 and AP-2 cargo-binding surfaces. $(A, B)$ Molecular details of the YXXØ and [DE]XXXL[LI] interaction surfaces on AP-2. The TGN38-derived YQRL signal cocrystalized with the AP-2 $\mu 2$-C domain (PDB ID: 1BXX) (Owen and Evans 1998) and the CD4 dileucine signal bound to the AP-2 heterotetramer core (PDB ID: 2JKR) (Kelly et al. 2008). Amino- and carboxy-terminal ends of the peptide signals (yellow) in stick representation are shown with oxygen colored red and nitrogen colored blue. The binding pockets for key anchor residues are outlined with white dashed ovals. $(C)$ Molecular surface of the ternary AP-1 $\mu 1$ subunit•HIV-1 Nef•MHC-1 complex that stabilizes the noncanonical YXXØ signal in MHC-1 in the absence of an effective hydrophobic $\varnothing$ residue. (D) Proximity of posttranslationally phosphorylated (blue) or ubiquitinated (red) residues identified within or adjacent to different primary-sequence-based sorting signals in the indicated proteins, including the protease-activated receptor 1 (PAR1), the cation-independent mannose 6phosphate receptor (CI-MPR), and amyloid precursor protein (APP). Sorting signals are shown in color-coded bold type and the number of amino acid residues preceding or following the individual signals from the transmembrane ( $\mathrm{Tm}$ ) domain are indicated. All modifications listed in the PhosphoSitePlus mass spectrometry database (Hornbeck et al. 2004). 

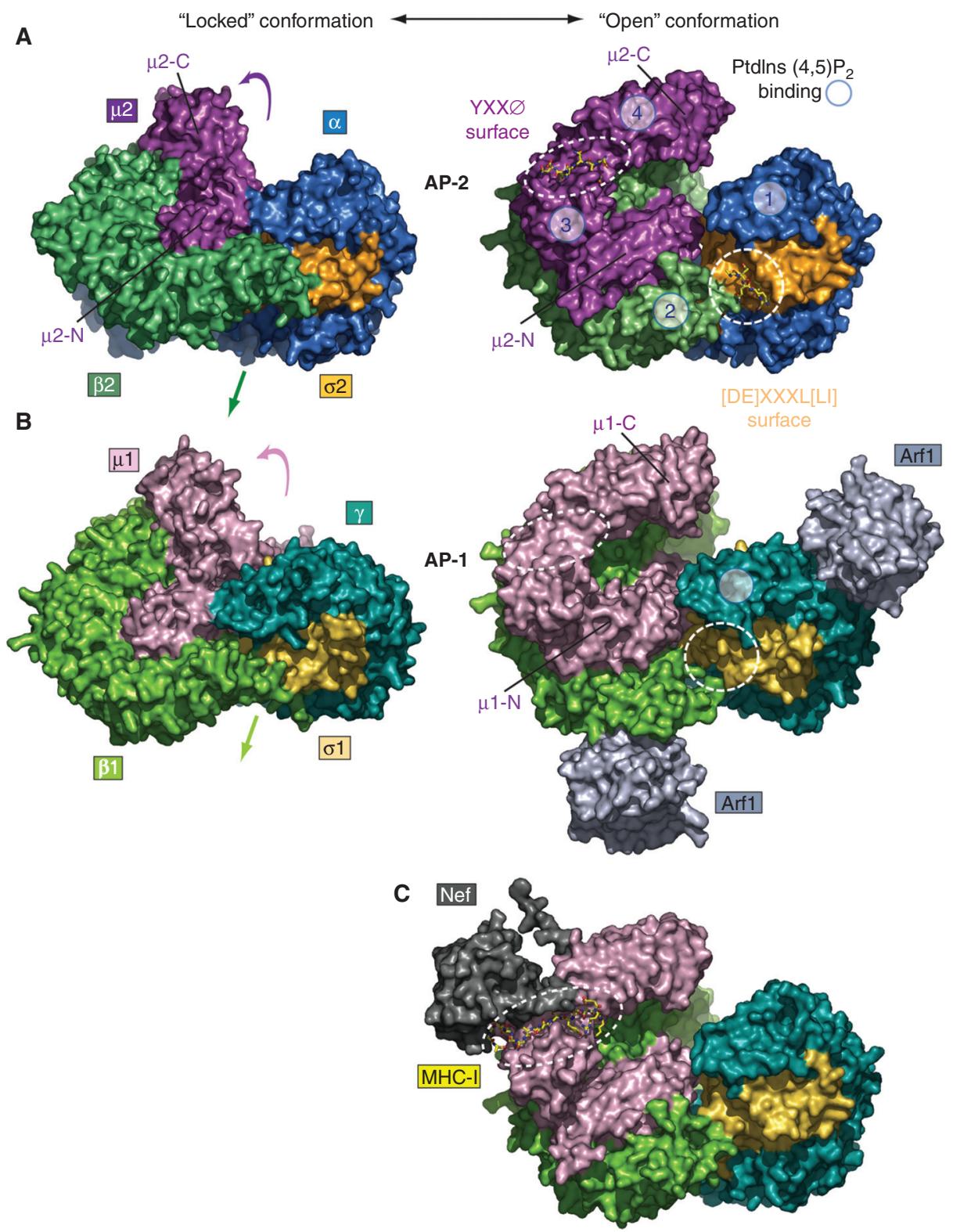

Figure 3. Allosteric-regulated exposure of the AP-1 and AP-2 cargo-binding surfaces. $(A, B)$ Space-filling surface representations of AP-1 and AP-2 heterotetramers highlight the conformational transitions on conversion from the AP-2 "locked" state (PDB ID: 2VGL) (Collins et al. 2002) to the open state (PBD ID: 2XA7) (Jackson et al. 2010). A view of the membrane-attached face is depicted and the four subunits colored to reflect structural and functional conservation. Opening chain movements are indicated (colored arrows). Cocrystalized YXXØ and [DE]XXXL[LI] peptide signals (rendered in yellow stick representation) are delimited with white dashed circles. The relative position of the four spatially discrete $\operatorname{PtdIns}(4,5) \mathrm{P}_{2}$ binding sites that only become coplanar on transition to the open conformation in AP-2 are circled and numbered. Similar bottom-up views of the AP-1 heteroterameric core in the closed (PDB ID: 1W63) (Heldwein et al. 2004) and open (PDB ID: 4HMY) (Ren et al. 2013) conformations, with an Arfl GTPase contacting each large chain trunk domain. The location of the PtdIns(4)P-binding site on the $\gamma$ subunit (Heldwein et al. 2004) is circled in the open conformation. $(C) \mathrm{A}$ composite molecular model of the AP-1 $\mu 1 \bullet$ Nef $\bullet$ MHC-I ternary complex (PDB ID: 4EN2) (Jia et al. 2012), rendered with the AP-2 open conformation backbone model, shown in similar orientation to $A$ and $B$. Positioning of the MHC-I peptide (yellow sticks) is indicated with a white dashed oval. 
L.M. Traub and J.S. Bonifacino

\section{RECOGNITION OF LINEAR MOTIFS BY AP-1}

Studies on signal recognition by AP-1 have revealed striking similarities but also important differences in comparison with AP-2. AP-1 is a component of clathrin coats associated with the TGN and endosomes, and has been implicated in many pathways, including bidirectional transport between the TGN and endosomes (Hirst et al. 2012), export from the TGN to the plasma membrane (Guo et al. 2013), and polarized sorting from the TGN or endosomes to the basolateral domain of epithelial cells (Folsch et al. 1999; Carvajal-Gonzalez et al. 2012) and the somatodendritic domain of neurons (Dwyer et al. 2001; Margeta et al. 2009; Farias et al. 2012). AP-1 has been additionally shown to complement the role of AP-2 in endocytosis of synaptic vesicle proteins at the neuronal presynaptic terminal (Kim and Ryan 2009). The function of AP- 1 in these pathways also involves recognition of linear motifs by mechanisms that are similar to those of AP-2. YXX $\varnothing$ and [DE]XXXL[LI] motifs bind to conserved sites on the $\mu 1$ (Ohno et al. 1995; Carvajal-Gonzalez et al. 2012; Farias et al. 2012) and $\gamma-\sigma 1$ subunits (Janvier et al. 2003; Doray et al. 2007; Mattera et al. 2011), respectively. Moreover, the AP-1 core also occurs in equilibrium between locked (Heldwein et al. 2004) and open conformations (Fig. 3B) (Ren et al. 2013). On the other hand, the regulation of membrane recruitment and conformational activation are quite different. AP-1 binds phosphatidylinositol 4-phosphate (PtdIns(4)P), a phosphoinositide that is enriched in the TGN and endosomes, through a site on the $\gamma$ subunit (Wang et al. 2003; Heldwein et al. 2004). However, this binding is too weak for efficient recruitment to membranes. Instead, the main determinant of AP-1 recruitment to membranes is binding to the GTP-bound, activated form of Arfl (Stamnes and Rothman 1993; Traub et al. 1993). Other Arf-family members, including Arfrp1 (also known as Arl3) (Guo et al. 2013), may also play roles in AP-1 membrane recruitment. Exchange of GTP for GDP on Arf1 exposes an $N$-myristoylated $\alpha$ helix that inserts into membranes and rearranges the switch I and II regions such that they can bind AP-1. A recent study has identified two binding sites for Arf1 on the trunk domains of the $\gamma$ and $\beta 1$ subunits of AP-1 that contribute to recruitment of this complex to membranes (Ren et al. 2013). Strikingly, Arf1 not only promotes AP-1 membrane recruitment but also drives the conformational opening of the core that allows binding of YXXØ and [DE]XXXL[LI] motifs (Ren et al. 2013). This conformational change appears to involve pivoting on a third Arfl-binding site located on a different face of the $\gamma$ trunk (Ren et al. 2013). The cooperativity of these interactions is further evidenced by the observation that both YXXØ and [DE]XXXL[LI] promote binding to each other, as well as binding of Arf1 to AP-1 (Lee et al. 2008a). The amino acids that bind Arf1 are perfectly conserved in the $\beta 2$ subunit and partially conserved in the $\alpha$ subunit of AP-2, but the role of Arf-family members in AP-2 membrane recruitment is controversial (Krauss et al. 2003; Paleotti et al. 2005). YXXØ-, [DE]XXXL[LI]-, and Arf-binding sites are also well conserved in AP-3 (Mattera et al. 2011; Mardones et al. 2013; Ren et al. 2013), an endosome-associated adaptor involved in cargo sorting to lysosomes and lysosome-related organelles, indicating that this complex might function by a similar mechanism.

\section{Nef: A COOPERATIVE MODIFIER OF SIGNAL-ADAPTOR INTERACTIONS}

The mechanism of action of the Nef protein of human immunodeficiency virus 1 (HIV-1) exemplifies another means of regulating signal recognition by $\mathrm{AP}-1$ and $\mathrm{AP}-2$. Expression of Nef early in the infection cycle of HIV-1 causes down-regulation of CD4 and class I molecules of the major histocompatibility complex (MHC-I) from the surface of the host cells (i.e., T lymphocytes and macrophages) (Tokarev and Guatelli 2011). Remarkably, whereas Nef-induced CD4 down-regulation involves enhanced AP-2-dependent internalization (Jin et al. 2005; Chaudhuri et al. 2007), MHC-I down-regulation occurs by AP-1-dependent delivery of intracellular MHC-I from the TGN to endosomes (Roeth et al. 2004; Lubben et al. 2007). In both 
Cargo Recognition in Clathrin-Mediated Endocytosis

cases, the proteins are eventually transported to lysosomes for degradation. These down-regulation events involve cooperative formation of tripartite CD4 $\bullet \mathrm{Nef} \bullet \mathrm{AP}-2$ and $\mathrm{MHC}-\mathrm{I} \bullet \mathrm{Nef} \bullet \mathrm{AP}-1$ complexes. In the CD4•Nef•AP-2 complex, a Nef carboxy-terminal flexible loop contains a [DE]XXXL[LI] motif that bind to the canonical dileucine-binding site on $\alpha-\sigma 2$ (Chaudhuri et al. 2007) and other residues that bind to a basic patch on the trunk domain of $\alpha$ (Chaudhuri et al. 2009). In between the dileucine and diacidic motifs there are additional hydrophobic residues that also bind to AP-2 likely via $\sigma 2$ (Fig. 2B) (Jin et al. 2012). The Nef loop thus exemplifies how a long sequence containing both canonical and noncanonical elements can interact with AP-2. The dileucine motif in the CD4 tail cannot interact with the canonical dileucine-binding site on $\alpha-\sigma 2$ because the serine at position -5 from the first leucine in CD4 (Fig. 2D) is normally not phosphorylated and the dileucine-binding site on $\alpha-\sigma 2$ is occupied by the Nef loop. Instead, the dileucine motif in the CD4 tail binds to a hydrophobic patch on another region of Nef (Grzesiek et al. 1996). The cooperativity in the assembly of the tripartite complex (Chaudhuri et al. 2009) predicts the occurrence of another interaction of CD4 with AP-2 that remains to be identified. The recent resolution of the structure of the MHC-I cytosolic domain in a ternary complex with Nef and the $\mu 1$ subunit of AP- 1 has revealed a different type of cooperative assembly (Jia et al. 2012). In this complex, a noncanonical tyrosine residue in the MHC-I tail occupies the binding pocket for the tyrosine residue of YXX $\varnothing$ signals on $\mu 1$ (Figs. 2C and 3C). The rest of the MHC-I tail binds into a groove at the Nef- $\mu 1$ interface (Jia et al. 2012). These observations raise the intriguing possibility that other cellular proteins could promote interactions of cytosolic domains with adaptors in a manner similar to Nef.

\section{ALTERNATIVE TYROSINE-BASED SIGNAL RECOGNITION BY PTB-DOMAIN-TYPE CLASPS}

Although the [FY]XNPX[YF] signal delineated in the low-density lipoprotein (LDL) receptor
(FDNPVY) first showed the importance of an anchor tyrosine to cue internalization (Davis et al. 1986), this signal is actually recognized quite differently from YXXØ signals. Substitution of the carboxy-terminal tyrosine at position 0 with phenylalanine (or even tryptophan) (Davis et al. 1986) has little effect on internalization, whereas a cysteine or alanine change diminishes uptake to that of a cytosolically truncated receptor (Davis et al. 1986; Chen et al. 1990). Several transmembrane cargoes bearing [FY]XNPX[YF] signals naturally have a phenylalanine at this position (like amnionless [Pedersen et al. 2010], Opo [Bogdanovic et al. 2012], P-selectin [Ghai et al. 2013], ROMK [Fang et al. 2009], Sanpodo [Tong et al. 2010], and TAT-1 [Nilsson et al. 2011]). Instead of AP-2, these [FY]XNPX[YF] signals are decoded by monomeric CLASPs with a phosphotyrosine-binding (PTB) domain, such as Dab2, ARH (alternatively designated LDLRAP 1), and Numb (Fig. 1) (McMahon and Boucrot 2011; Reider and Wendland 2011). The modular PTB domain in these CLASPs is similar to that originally identified in signal transduction proteins, but differs in a preference for unphosphorylated over phosphorylated tyrosine. The recent resolution of the structure of the liganded ARH PTB domain (Dvir et al. 2012) explains clearly why either tyrosine or phenylalanine can be accommodated at position 0 , in stark contrast to YXXØ signals, where phenylalanine cannot replace tyrosine (Fig. 4). To engage the $[\mathrm{YF}]$ side chain at position 0 , ARH displays a largely hydrophobic-lined acceptor cavity (Dvir et al. 2012). This is dissimilar to signal transduction PTB domains, which have an overall basic character to the larger phosphotyrosine-accommodating site (Farooq and Zhou 2004; Uhlik et al. 2005). In ARH, the tyrosine hydroxyl hydrogen bonds to a single, noncovalent water molecule to permit packing into the nonpolar surface (Fig. 4), which would be unnecessary for a phenylalanine.

A chemical distinction between tyrosine and phenylalanine at position 0 is that only the former can be posttranslationally phosphorylated. Because endocytic PTB domains cannot well accommodate the bulky, charged phospho- 
L.M. Traub and J.S. Bonifacino

\section{A}

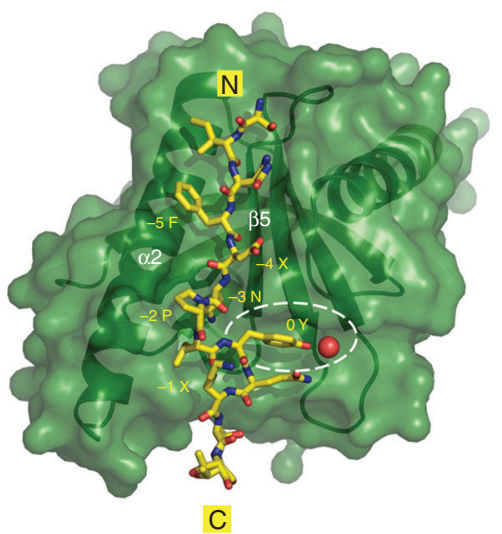

C

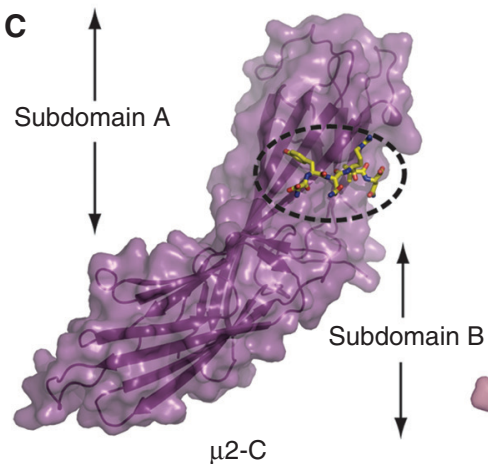

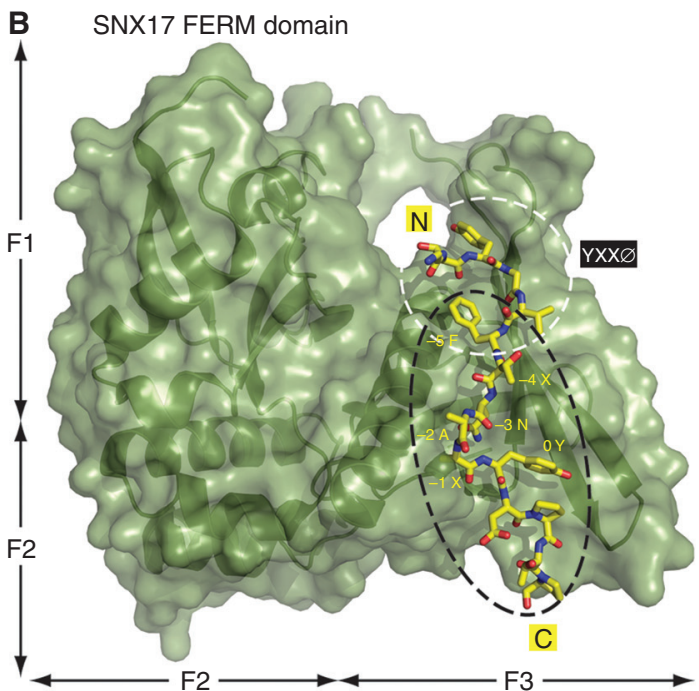

D

D

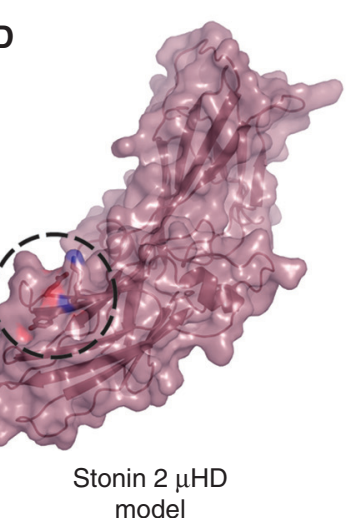

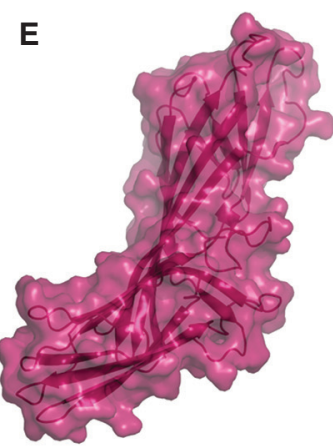

Syp $1 \mathrm{p} \mu \mathrm{HD}$

Figure 4. PTB domains and $\mu$ HDs in cargo signal recognition. (A) Combined ribbon and space-filling surface representation of the ARH PTB domain bound to the LDL receptor SINFDNPVYQKT sorting-signal peptide shown in stick representation (PDB ID: 3SO6) (Dvir et al. 2012). The location of a water molecule hydrogen bonded to the position 0 tyrosine is indicated by a red sphere within the marked PTB-domain tyrosine-binding site. $(B)$ Combined ribbon and surface representation of the SNX17 FERM-like domain complexed with the TYGVFTNAAYDPT signal from P-selection (PDB ID: 4GXB) (Ghai et al. 2013). Shown in the same relative orientation as $A$ with the positioning of the F1-F3 subdomains indicated and the YXXØ and [FY]XNPX[YF] interaction surfaces highlighted. $(C-E)$ Combined ribbon and surface representations of the AP-2 $\mu 2$ subunit bound to the YQRL signal from TGN38 (PDB ID:1BXX) (Owen and Evans 1998), a homology model of the human Stonin 2 mHD generated by Phyre ${ }^{2}$ (Kelley and Sternberg 2009), and the Saccharomyces cerevisiae Syp $1 \mathrm{p}$ $\mu \mathrm{HD}$ (PDB ID: 3G9H) (Reider et al. 2009). The relative positioning of the YXXØ interaction surface in subdomain A on $\mu 2$, and the biochemically defined synaptotagmin 1 C2A-binding site on subdomain B of stonin 2 (Jung et al. 2007) are indicated. Three side chains on the stonin $2 \mu$ HD (Lys783, Tyr784, Glu785) implicated in C2A binding are highlighted.

tyrosine, this reversible modification can potentially govern sorting efficiency into nascent clathrin-coated structures, as with the YXXØ signal. There is some evidence for this for the LDL receptor-related protein 1 (LRP1), which binds to different partners depending on the phosphotyrosine status (Betts et al. 2008; Guttman et al. 2009). In Drosophila, the YTNPAF signal in the tetraspanin Sanpodo is recognized by Numb (Tong et al. 2010), whereas the 
FDNPVY signal in the scavenger receptor Draper is recognized by the PTB CLASP Ced-6 (Awasaki et al. 2006; Jha et al. 2102), and tyrosine phosphorylation regulates its uptake into cells (Fujita et al. 2012). Intriguingly, discoverymode mass spectrometry indicates that Tyr807, the LDL receptor tyrosine 0 , is phosphorylated in $>125$ separate studies (Hornbeck et al. 2004). Because the anchor Tyr20 of the transferrin receptor YXXØ (YTRF) signal is similarly phosphorylated in $>1000$ mass spectrometry analyses, focal tyrosine phosphorylation during signal relay from the cell surface might, through exclusion, underlie the formation of compositionally and/or kinetically distinct coated vesicles (Fig. 2D) (Cao et al. 1998; Mundell et al. 2006; Puthenveedu and von Zastrow 2006; Liu et al. 2010).

The structural role of all the other conserved side chains in the [FY]XNPX[YF] signal is also known. The leading -5 position tyrosine/ phenylalanine packs into a complementary hydrophobic site generated principally by the socalled "selectivity" $\alpha 2$ helix, and usually involving a projecting PTB-domain aromatic side chain that bisects the interaction surfaces for the -5 tyrosine/phenylalanine and the -3 asparagine and -2 proline (Fig. 4). There is also additional binding energy derived from an antiparallel $\beta$ augmentation, hydrogen bonding to the canonical $\beta 5$ strand of the PTB domain. Yet, because these involve only main-chain contacts, the $\beta 5$ strand participates rather "nonselectively" in cargo recognition (Dvir et al. 2012). At the carboxy-terminal end of the short signal $\beta$ strand, the central -3 asparagine makes an intramolecular bond with tyrosine 0 to redirect the peptide main-chain configuration into a type I $\beta$ turn, strongly facilitated by the following -2 proline. Overall, this structures the sorting signal to optimally engage the cognate interface of the PTB domain (Fig. 4).

\section{MODULATION OF [FY]XNPX[YF] SIGNAL RECOGNITION BY UBIQUITINATION}

Another interesting mode of modulation of the trafficking behavior of the LDL receptor FDNPVY signal is by targeted ubiquitination by an E3 ubiquitin ligase designated IDOL (for inducible degrader of the LDL receptor) (Zelcer et al. 2009). The recognition site for IDOL overlaps the FDNPVY signal; this is because substrate recognition in this particular E3 ligase stems from an atypical FERM (band 4.1/ ezrin/radixin/moesin) domain that precedes the catalytic carboxy-terminal RING domain (Calkin et al. 2011; Sorrentino et al. 2011). Prior structural work on FERM domains from actinregulating proteins like ezrin and talin revealed a tripartite fold, with the so-called F3 subdomain structurally analogous to the PTB domain (Pearson et al. 2000). The talin F3 subdomain binds to the NPXY signal in $\beta$ integrins (Wegener et al. 2007), using, in part, the same basic structural arrangement as seen in ARH. Likewise, IDOL contacts physically the LDL receptor FDNPVY sorting signal, and signals in the related VLDL and ApoER2 receptors (Hong et al. 2010). The core components are also phylogenetically conserved in insects (Hong et al. 2010; Calkin et al. 2011). The IDOL ubiquitin ligase targets sites that are adjacent to the FDNPVY signal: two (Lys809) or 11 (Cys819) residues following Tyr807 (Fig. 2D) (Zelcer et al. 2009). The functional consequence of this ubiquitination is redirection of the LDL receptor to lysosomes for degradation at the expense of efficient recycling (Zelcer et al. 2009). Remarkably, initial results suggest that the IDOL-mediated polyubiquitin signal attached to the LDL receptor reroutes the protein from clathrindependent to clathrin-independent internalization, clearly inactivating the FDNPVY signal (Scotti et al. 2013).

\section{OPERATION OF [FY]XNPX[YF] SIGNALS ON ENDOSOMES}

Functionally analogous to YXXØ signals, [FY]XNPX[YF] signals can direct endosomal sorting events. This can happen in at least two ways: indirectly through interaction of PTBdomain-containing CLASPs with AP-1, and directly through recognition by FERM-like domain-containing sorting nexin (SNX) proteins. In one process in polarized epithelial cells, the respective adaptors, $\mathrm{ARH}$ and a variant of $\mathrm{AP}-1$ 
having the $\mu 1 \mathrm{~B}$ subunit isoform (AP-1B), cooperate for differential sorting to the basolateral membrane from endosomes (Kang and Folsch 2011). Yet the capability of ARH to mesh with both AP-1B and AP-2 depends on the sole ARH $\beta$-subunit interaction motif (He et al. 2002; Mishra et al. 2005; Edeling et al. 2006; Schmid et al. 2006); mammalian $\beta 1$ and $\beta 2$ are $\sim 85 \%$ identical and functionally interchangeable (Keyel et al. 2008; Li et al. 2010). Consequently, the surface on the $\beta 1$ appendage that ARH binds to is fully conserved in $\beta 2$. ARH also has a broadly basic surface perpendicular to the [FY]XNPX[YF]-binding site that could accommodate different phosphoinositides rather than being tailored for a stereospecific isomer.

Another example of cooperation between a PTB-domain CLASP and AP-1 is provided by Numb. This protein (and the redundant paralog Numb-like) is involved in Notch signaling (Berdnik et al. 2002), cell adhesion, migration (Wang et al. 2009), and morphogenesis (Berdnik et al. 2002; Bogdanovic et al. 2012). Numb can also function on endosomes (Smith et al. 2004; Nilsson et al. 2008; McGill et al. 2009; Cotton et al. 2013; Couturier et al. 2013), and clearly has endosome-located binding partners, although biochemical interactions revolve principally around AP-2 and associated proteins (Krieger et al. 2012). The plasma membraneand endosome-associated chordate Numb isoforms are different splice variants (Dho et al. 1999) and regulated by posttranslational phosphorylation (Smith et al. 2007; Sorensen and Conner 2008). In Drosophila, Numb cooperates with AP-1 to control Sanpodo trafficking on endosomes (Cotton et al. 2013; Couturier et al. 2013) but, in this case, basolateral recycling is prevented (Cotton et al. 2013), contrary to ARH.

A different mechanism is the recognition of [FY]XNPX[YF] signals by SNX proteins, specifically by the paralogs SNX17, SNX27, and SNX31 (Ghai et al. 2011, 2013; Bottcher et al. 2012). SNXs are a diverse class of endocytic proteins unified by the presence of a phox-homology (PX) domain selective for endosomal phosphatidylinositol 3-phosphate (PtdIns(3)P) (Cullen 2008; Teasdale and Collins 2012). SNX17, SNX27, and SNX31 stand apart from the other family members by uniquely containing an atypical FERM domain after the PX fold. The LDL receptor signal directly engages the SNX17 FERM domain (Stockinger et al. 2002; Burden et al. 2004), as do the [FY]XNPX[YF] signals in P-selectin (Florian et al. 2001; Knauth et al. 2005; Ghai et al. 2013), APP (Lee et al. 2008b), $\beta$ integrins (Bottcher et al. 2012; Steinberg et al. 2012), and LRP1 (van Kerkhof et al. 2005; Donoso et al. 2009) in a phosphorylationinhibited manner (Betts et al. 2008). The structure of the SNX17 FERM domain complexed with the P-selectin sorting signal (Ghai et al. 2013) confirms both that the F3 subdomain resembles the PTB-domain fold and that peptide binding conforms to conventional structural rules (Fig. 4). Compartmental recognition of [FY]XNPX[YF] signals is assured by the preceding PX domain, which favors endosomal PtdIns(3)P (Knauth et al. 2005; van Kerkhof et al. 2005; Ghai et al. 2011). Because of the proximity of the acceptor lysine, the IDOLubiquitinated FDNPVY signal in the LDL receptor may not be recognized by SNX17, explaining the diminished recycling. Strikingly, several different endocytic signals have internal or proximate lysine residues known to be ubiquitinated (Fig. 2D). This suggests that ubiquitindependent masking of linear sequences might be another common regulatory mechanism.

If the bulk of PTB-like domains engage [FY]XNPX[YF] signals with common structural features and a conserved binding mode, how is specificity attained? The ARH and SNX17 structures highlight another general principle for signal recognition: directly flanking residues at the amino- or carboxy-terminal end of the core sorting signal allow tailored recognition of a certain tertiary-structured binding partner. For instance, P-selectin contains a bona fide $\mu 2$-binding YXXØ-type YGVF signal interleaved with the FTNAA[YF] signal (Owen et al. 2001). In the SNX17 crystal, this peptide sequence also packs against the FERM domain F3 subdomain (Fig. 4) (Ghai et al. 2013), explaining why this could not simultaneously be recognized by AP- 1 or AP- 2 . The $\beta 1$-integrin chain similarly uses a sequence tract preceding NPKY to optimally engage SNX17 (Bottcher 
Cargo Recognition in Clathrin-Mediated Endocytosis

et al. 2012). Such extended contacts facilitate optimal conformational selection by allowing domains to discriminate between a large array of potentially similar unstructured binding peptides and select between subtly different signals. Alternatively, restricted expression patterns or temporal induction can provide specificity, as with IDOL being induced by LXR transcription factor activation (Zelcer et al. 2009).

\section{DISTANT RELATIONS: $\mu$-HOMOLOGY DOMAIN CLASPS}

Because of the pivotal role of the $\mu$ subunit in AP-1-AP-4 cargo selection, the fact that two other protein classes deposited at clathrin assembly centers, the stonins and muniscins, also contain a $\mu$-homology domain ( $\mu \mathrm{HD})$ (Fig. 4) is highly suggestive of further cargo recognition capabilities. The most closely related $\mu \mathrm{HD}$ is found in stonins (Andrews et al. 1996; Martina et al. 2001; Walther et al. 2001); the human stonin $2 \mu \mathrm{HD}$ is $\sim 30 \%$ identical to the $\mu 2-\mathrm{C}$ domain of AP-2. In contrast, the muniscin $\mu \mathrm{HD}$ is $<10 \%$ identical to $\mu 2$ accounting for the original designation $\mathrm{FCH}$ domain "only" (Fcho), as the initial sequence comparisons failed to identify the structural homology (Katoh 2004; Henne et al. 2007). The $\mu \mathrm{HD}$ of the yeast muniscin Syp1p is $\sim 14 \%$ identical to the stonin 2 domain, but neither has a similarly positioned longin-like $\mu-\mathrm{N}$ domain, which coassembles with the $\beta$ chain within the adaptor core. The stonin $\mu \mathrm{HD}$ is preceded by a phylogenetically conserved tract of $\sim 140$ residues known as the stonin-homology domain (Martina et al. 2001) currently of unknown structure or function.

The stonins are ubiquitously expressed in chordate tissues but seem most critical in neurons; mutant alleles or silencing produces neurological phenotypes in flies, worms, and mice (Stimson et al. 2001; Estes et al. 2003; Mullen et al. 2012; Kononenko et al. 2013). At the synapse, tight exo-endocytic coupling maintains a pool of neurotransmitter-filled synaptic vesicles. Here, transmembrane cargo recognition is critical as synaptic vesicles have a highly defined protein composition (Takamori et al. 2006), and there is a remarkably conserved packaging stoichiometry for some transmembrane proteins within reforming synaptic vesicles (Takamori et al. 2006; Mutch et al. 2011). Synaptotagmin 1 is a vesicle-associated, $\mathrm{Ca}^{2+}$ responsive bilayer fusion regulator and therefore necessarily packaged into each regenerating synaptic vesicle following exocytosis. Biochemical and functional evidence indicates that the $\mathrm{C} 2$ domains of synaptotagmin 1 bind physically to the stonin $2 \mu \mathrm{HD}$ (Martina et al. 2001; Walther et al. 2001; Diril et al. 2006; Jung et al. 2007). In neurons, the two proteins colocalize in puncta, and proper subcellular localization of SNT-1 depends on UNC-41 (the respective nematode orthologs) but not vice versa (Mullen et al. 2012). Because synaptotagmin (snt-1)-null worms phenocopy stonin (stn-1) unc-41) mutants (Mullen et al. 2012), a principal task of stonins is likely to promote uptake of synaptotagmin at nerve terminals.

Still, there is current controversy over precisely which presynaptic cargoes stonin 2 sorts. Worms with both $s n t-1$ and $u n c-41$ genes disrupted have a more severe phenotype than with either single mutation alone (Mullen et al. 2012). And forced SNT-1 overexpression does not rescue the unc-41 phenotype, unlike in Drosophila (Fergestad and Broadie 2001). Together, this suggests stonins do more than just sort synaptotagmin. A systematic CLASP RNAi screen of cultured neurons suggests that stonin 2 is actually the major adaptor for synaptic vesicle cargoes (Willox and Royle 2012), implying that it recognizes a bigger set of transmembrane proteins. But, of the synaptic vesicle constituents, only synaptotagmin 1 coimmunoprecipitates robustly with stonin 2 (Kononenko et al. 2013). And the subcellular phenotype of stonin 2-nullizygous mice disputes the notion of a general-purpose CLASP; synaptotagmin but not VAMP 2 selectively disperses over the presynaptic surface (Kononenko et al. 2013). A future challenge is to rationalize these discrepant findings.

For the muniscins, cargo partners are documented (Reider et al. 2009; Umasankar et al. 2012), but the $\mu$ HDs are otherwise different 
L.M. Traub and J.S. Bonifacino

in their interaction networks. This is because these $\mu$ HDs are not solely engaged in cargo binding. Both the yeast and the chordate muniscin $\mu$ HDs establish direct contacts with several early-arriving pioneer components of the clathrin coat (Reider et al. 2009; Henne et al. 2010; Mulkearns and Cooper 2012; Umasankar et al. 2012). The crystal structure of the Syp 1p $\mu \mathrm{HD}$ leaves no doubt about the structural homology with $\mu 2$ (Fig. 4). Still, the precise interaction surface on the $\mu \mathrm{HD}$ remains to be mapped. Therefore, it is not unambiguously resolved whether cargo and endocytic proteins use the same interaction surface(s) to associate with muniscins at the plasma membrane. Certainly for the stonin $2 \mu \mathrm{HD} \cdot \mathrm{C} 2 \mathrm{~A} / \mathrm{B}$ interaction, both partners are folded domains, distinguishing this contact from the short peptide-based, extended conformation interactions described above.
Elucidation of the molecular basis for selection of endocytic SNAREs has provided new structural insights into recognition of folded sorting signals. Because the immediate fate of donor transport vesicles is fusion with an acceptor compartment, proper packaging of SNAREs is vital. One mechanism to assure selective SNARE capture uses a disordered region of a dedicated CLASP to engage a broad molecular surface of a particular SNARE. The antithesis of the standard mode of engagement, this is how Hrb binds to VAMP 7 (Pryor et al. 2008) and, analogously, how the usually disordered hinge of the AP-3 $\delta$ subunit structures around the globular regulatory VAMP 7 longin domain to assure packaging of only a four-member cis-SNARE helical bundle (Fig. 5A) (Kent et al. 2012). The "signal" here is a radial groove along the longindomain surface accessed by either Hrb, the $\delta$ hinge, or intramolecularly by VAMP 7 itself in
A $\quad$ VAMP 7

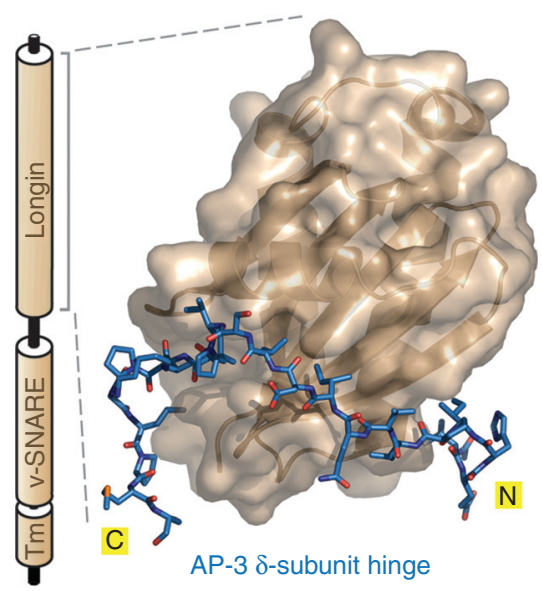

B VAMP 8

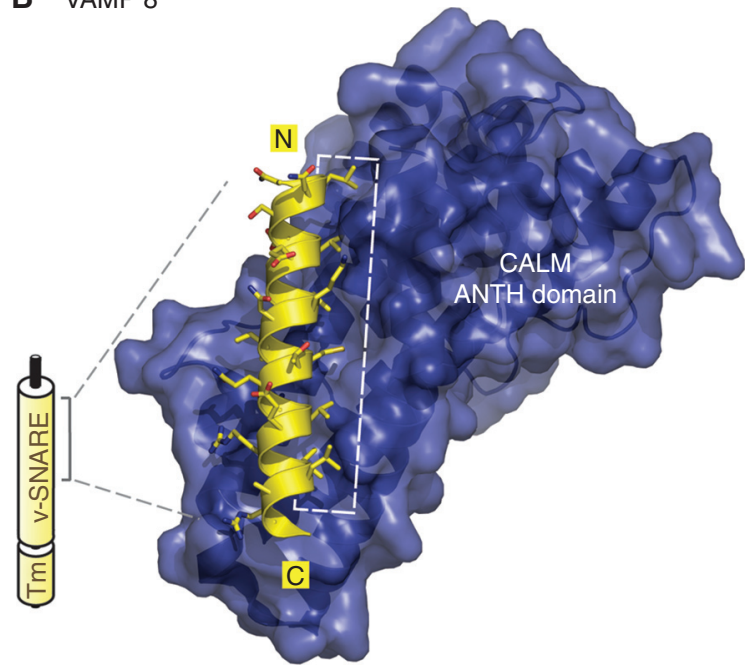

Figure 5. Decoding folded endocytic sorting signals. (A) Schematic representation of the overall architecture of VAMP 7 with the amino-terminal longin domain, the vesicle-SNARE ( $v$-SNARE) helical segment, and the transmembrane (Tm) domain indicated. A combined ribbon and surface representation of the globular VAMP 7 longin-domain "signal" bound by the extended AP- $3 \delta$-subunit hinge polypeptide (blue; in stick representation) is also shown (PDB ID: 4AFI) (Kent et al. 2012). Notice the insertion of several hydrophobic side chains from the $\delta$ hinge into complementary acceptor cavities arrayed around the regulatory longin-domain circumference. (B) Schematic of the architecture of VAMP 8, which lacks the autoinhibitory longin domain. A representation of the amino-terminal portion (residues 15-38) of the $\alpha$-helical v-SNARE domain of VAMP 8 complexed with the $\alpha$-solenoid folded ANTH domain from CALM (PDB ID: 3ZYM) (Miller et al. 2011). The structured VAMP 8 amphipathic $\alpha$ helix orients seven aliphatic side chains to insert into a vertical groove along the ANTH surface (white dashed line). 
the autoinhibited conformation that precludes CLASP binding. In contrast, the $\alpha$-helical-solenoid fold of the CALM (and the neuronal paralog AP180) ANTH domain has evolved to selectively recognize the uncomplexed vesicle SNAREs VAMP 2, 3, and 8 (Koo et al. 2011; Miller et al. 2011). In this case, the single sixturn amphipathic $\alpha$-helical tract of VAMP 8 that physically contacts the ANTH domain (Fig. 5B) also participates in SNARE helical bundling, making the two interactions mutually exclusive.

\section{CONCLUDING REMARKS AND FUTURE PERSPECTIVES}

We are long past a primitive understanding of sorting signals governing coat-mediated endocytic trafficking. With elegant high-resolution structures of verified peptide sorting signals bound to their cognate interaction domains, the field has come of age. What is clear is that there is a rich variety of interaction possibilities to drive distinct sorting processes. The core primary-sequence sorting signals are four-to-six residues long, similar to the majority of eukaryotic linear motifs (ELMs) (Davey et al. 2012). Short linear sequences facilitate convergent evolution. But why is not only a single, optimized master signal present within all cargoes to be internalized from the cell surface? Certain pathogenic bacteria, for example, encode effector proteins injected into host cells, which become tyrosine phosphorylated and then bind to numerous distinct cellular SH2 domain-containing signaling regulators (Selbach et al. 2009). In general, these phosphopeptide sequences are more similar within bacteria than to the multiple endogenous SH2-binding proteins they have evolved to subvert. In fact, $\mathrm{SH} 2$ domains can be artificially tailored to bind phosphotyrosine signals considerably tighter (Kaneko et al. 2012). Similarly, interaction partners for clathrin-mediated endocytosis have evolved to permit relatively weak, transient but selective associations to enable efficient trafficking. It is evident then that cargo recognition folds are not optimally evolved to bind sorting signals with highest affinity. Hence, there is significant variation within and between operative signals, which have been favored to allow the flexibility and appropriate assembled dwell times necessary for normal trafficking operations. Other critical aspects of an expanded sorting-signal code are that it avoids direct competition between cargoes for uptake (Warren et al. 1998), permits discrimination between monomeric and complexed SNAREs, and allows synchronization of multiple traffic flows.

Moreover, if sorting depended solely on bimolecular cargo-coat interactions, the process would be highly error prone owing to promiscuous binding errors with related but inappropriate sequences (Ladbury and Arold 2012). And if the same signal operates at different sorting stations, it is implicit that information necessary to recruit the appropriate coat/adaptor is not the signal itself. Indeed, in AP-1 and AP2 , the cargo-recognition surfaces only become available once membrane association is established. One mechanism to increase accuracy is by temporal integration of several low-affinity contacts through spatially separate contact surfaces to guard against random noise, in the form of nonspecific univalent engagement by related (or unrelated) proteins. This robust recognition only under certain circumstances typifies selective binding of conditional peripheral membrane proteins (Moravcevic et al. 2012), and is often termed "coincidence detection" (Carlton and Cullen 2005) or a "dual-key strategy" (Itoh and De Camilli 2004). Coat assembly is therefore a probabilistic process, with increased likelihood of successful assembly with the more synchronous linked interactions at a nascent bud site. By binding to multiple adaptors or CLASPs, cargoes participate directly in the network, and thus modulate the coat assembly process (Mettlen et al. 2010). A corollary of this densely wired redundant network is that gene silencing or RNAi of numerous individual CLASPs does not have a dramatic penetrant effect on endocytosis (Garcia et al. 2001; Kang-Decker et al. 2001; Morris et al. 2002; Kamikura and Cooper 2003; Holmes et al. 2007; Koh et al. 2007; Wang et al. 2008; Chen et al. 2009; Mullen et al. 2012; Pozzi et al. 2012; Scotland et al. 2012; Suzuki et al. 2012; Umasankar et al. 2012; Kononenko et al. 2013; Tsushima et al. 2013). Rather, subtle or tissue-specific defects are manifest linked to im- 
proper signal relay by the cargo affected. This concept is also concordant with pathogenic microorganisms requiring different elements of the endocytic machinery for successful entry and infection (Eto et al. 2008; Bhattacharyya et al. 2011; Bonazzi et al. 2011; Fukumatsu et al. 2012).

It is unlikely that we currently have a complete catalog of operational sorting signals. Ongoing functional analysis reveals that within specific cargo, alterations in relative residue spacing and even tolerated loss of invariant anchor residues can occur (Kozik et al. 2010; Gephart et al. 2011; Ortega et al. 2012; Wang et al. 2012). Other noncanonical neighboring side chains compensate under these circumstances. A general screen for cytosolic sequences able to promote efficient internalization of a surface reporter highlights several novel operational sequences, yet are still heavily dependent on AP-2 (Kozik et al. 2010). First, designated "RYR," appears initially to be an altered YXXØ-type sequence, superficially analogous to the YEQGL sequence in the P2X4 purinergic receptor (Royle et al. 2005). However, although the tyrosine in the RYR is the most vital side chain, it does not appear to bind to the YXXØ site on $\mu 2-\mathrm{C}$ subdomain A (Kozik et al. 2010). $\mu 2$ also binds to a basic stretch (devoid of aromatic residues) of the $\delta$ subunit of $\mathrm{GABA}_{\mathrm{A}}$ receptors (Gonzalez et al. 2012), so there is likely another contact surface for cargo recognition, as is evident on the $\mu 4$ subunit of AP-4 (Burgos et al. 2010). Then there are the completely novel operational sorting signals: NMDA receptors that incorporate a GluN3A subunit use a YWL sorting signal for internalization (Chowdhury et al. 2013). In this signal, the leading tyrosine can be mutated; it is not indispensable. Remarkably, although a Y971F substitution is defective, a phosphomimetic Y971E permits better AP-2 binding and internalization (Chowdhury et al. 2013). This, it seems, is a sorting signal stimulated by tyrosine phosphorylation. The signal may be related to the SWF tripeptide sequence at the end of the novel "WPK" signal, which is AP-2 and clathrin dependent (Kozik et al. 2010). In both, alanine substitution of the $\mathrm{W}[\mathrm{LF}]$ pair strongly inhibits internalization (Kozik et al. 2010; Chowdhury et al. 2013). Ordered packing of unstructured regions of a CLASP over a cargo surface could also be more widespread than currently appreciated, and may allow proteins with large intrinsically disordered regions together with a folded modular domain to display cargo selectivity for more than one signal type, just like the heterotetrameric adaptors.

\section{ACKNOWLEDGMENTS}

L.M.T. is supported by the extramural program of National Institutes of Health (NIH) (R01 DK53249). J.S.B. is supported by the intramural program of NICHD, NIH. We are grateful to Bertram Canagarajah, John Guatelli, Jim Hurley, David Owen, Xuefeng Ren, and Yong Xiong for providing atomic coordinate files.

\section{REFERENCES}

${ }^{*}$ Reference is also in this collection

Andrews J, Smith M, Merakovsky J, Coulson M, Hannan F, Kelly LE. 1996. The stoned locus of Drosophila melanogaster produces a dicistronic transcript and encodes two distinct polypeptides. Genetics 143: 1699-1711.

Awasaki T, Tatsumi R, Takahashi K, Arai K, Nakanishi Y, Ueda R, Ito K. 2006. Essential role of the apoptotic cell engulfment genes draper and ced-6 in programmed axon pruning during Drosophila metamorphosis. Neuron 50: 855-867.

Berdnik D, Torok T, Gonzalez-Gaitan M, Knoblich J. 2002. The endocytic protein $\alpha$-adaptin is required for Numb-mediated asymmetric cell division in Drosophila. Dev Cell 3: 221-231.

Betts GN, van der Geer P, Komives EA. 2008. Structural and functional consequences of tyrosine phosphorylation in the LRP1 cytoplasmic domain. J Biol Chem 283: 1565615664.

Bhattacharyya S, Hope TJ, Young JA. 2011. Differential requirements for clathrin endocytic pathway components in cellular entry by Ebola and Marburg glycoprotein pseudovirions. Virology 419: 1-9.

Bogdanovic O, Delfino-Machin M, Nicolas-Perez M, Gavilan MP, Gago-Rodrigues I, Fernandez-Minan A, Lillo C, Rios RM, Wittbrodt J, Martinez-Morales JR. 2012. Numb/Numbl-Opo antagonism controls retinal epithelium morphogenesis by regulating integrin endocytosis. Dev Cell 23: 782-795.

Boll W, Ohno H, Songyang Z, Rapoport I, Cantley LC, Bonifacino JS, Kirchhausen T. 1996. Sequence requirements for the recognition of tyrosine-based endocytic signals by clathrin AP-2 complexes. EMBO J 15: 57895795.

Bonazzi M, Vasudevan L, Mallet A, Sachse M, Sartori A, Prevost MC, Roberts A, Taner SB, Wilbur JD, Brodsky FM, et al. 2011. Clathrin phosphorylation is required 
for actin recruitment at sites of bacterial adhesion and internalization. J Cell Biol 195: 525-536.

Bonifacino JS, Traub LM. 2003. Signals for sorting of transmembrane proteins to endosomes and lysosomes. Annu Rev Biochem 72: 395-447.

Bottcher RT, Stremmel C, Meves A, Meyer H, Widmaier M, Tseng HY, Fassler R. 2012. Sorting nexin 17 prevents lysosomal degradation of $\beta 1$ integrins by binding to the ß1-integrin tail. Nat Cell Biol 14: 584-592.

Brett TJ, Traub LM, Fremont DH. 2002. Accessory protein recruitment motifs in clathrin-mediated endocytosis. Structure 10: 797-809.

Brown MS, Goldstein JL. 1979. Receptor-mediated endocytosis: Insights from the lipoprotein receptor system. Proc Natl Acad Sci 76: 3330-3337.

Burden JJ, Sun XM, Garcia AB, Soutar AK. 2004. Sorting motifs in the intracellular domain of the low density lipoprotein receptor interact with a novel domain of sorting nexin-17. J Biol Chem 279: 16237-16245.

Burgos PV, Mardones GA, Rojas AL, daSilva LL, Prabhu Y, Hurley JH, Bonifacino JS. 2010. Sorting of the Alzheimer's disease amyloid precursor protein mediated by the AP-4 complex. Dev Cell 18: 425-436.

Calkin AC, Goult BT, Zhang L, Fairall L, Hong C, Schwabe JW, Tontonoz P. 2011. FERM-dependent E3 ligase recognition is a conserved mechanism for targeted degradation of lipoprotein receptors. Proc Natl Acad Sci 108: 20107-20112.

Cao TT, Mays RW, von Zastrow M. 1998. Regulated endocytosis of G-protein-coupled receptors by a biochemically and functionally distinct subpopulation of clathrin-coated pits. J Biol Chem 273: 24592-24602.

Carlton JG, Cullen PJ. 2005. Coincidence detection in phosphoinositide signaling. Trends Cell Biol 15: 540-547.

Carvajal-Gonzalez JM, Gravotta D, Mattera R, Diaz F, Bay AP, Roman AC, Schreiner RP, Thuenauer R, Bonifacino JS, Rodriguez-Boulan E. 2012. Basolateral sorting of the coxsackie and adenovirus receptor through interaction of a canonical YXXPhi motif with the clathrin adaptors AP1A and AP-1B. Proc Natl Acad Sci 109: 3820-3825.

Chaudhuri R, Lindwasser OW, Smith WJ, Hurley JH, Bonifacino JS. 2007. Downregulation of CD4 by human immunodeficiency virus type $1 \mathrm{Nef}$ is dependent on clathrin and involves direct interaction of Nef with the AP2 clathrin adaptor. J Virol 81: 3877-3890.

Chaudhuri R, Mattera R, Lindwasser OW, Robinson MS, Bonifacino JS. 2009. A basic patch on $\alpha$-adaptin is required for binding of human immunodeficiency virus type $1 \mathrm{Nef}$ and cooperative assembly of a CD4-Nef-AP2 complex. J Virol 83: 2518-2530.

Chen WJ, Goldstein JL, Brown MS. 1990. NPXY, a sequence often found in cytoplasmic tails, is required for coated pit-mediated internalization of the low density lipoprotein receptor. J Biol Chem 265: 3116-3123.

Chen H, Ko G, Zatti A, Di Giacomo G, Liu L, Raiteri E, Perucco E, Collesi C, Min W, Zeiss C, et al. 2009. Embryonic arrest at midgestation and disruption of Notch signaling produced by the absence of both epsin 1 and epsin 2 in mice. Proc Natl Acad Sci 106: 13838-13843.

Chowdhury D, Marco S, Brooks IM, Zandueta A, Rao Y, Haucke V, Wesseling JF, Tavalin SJ, Perez-Otano I. 2013.
Tyrosine phosphorylation regulates the endocytosis and surface expression of GluN3A-containing NMDA receptors. J Neurosci 33: 4151-4164.

Collawn JF, Stangel M, Kuhn LA, Esekogwu V, Jing SQ, Trowbridge IS, Tainer JA. 1990. Transferrin receptor internalization sequence YXRF implicates a tight turn as the structural recognition motif for endocytosis. Cell 63: $1061-1072$.

Collawn JF, Kuhn LA, Liu LF, Tainer JA, Trowbridge IS. 1991. Transplanted LDL and mannose-6-phosphate receptor internalization signals promote high-efficiency endocytosis of the transferrin receptor. EMBO J 10: 3247-3253.

Collins BM, McCoy AJ, Kent HM, Evans PR, Owen DJ. 2002. Molecular architecture and functional model of the endocytic AP2 complex. Cell 109: 523-535.

Conner SD, Schmid SL. 2002. Identification of an adaptorassociated kinase, AAK1, as a regulator of clathrin-mediated endocytosis. J Cell Biol 156: 921-929.

Cotton M, Benhra N, Le Borgne R. 2013. Numb inhibits the recycling of Sanpodo in Drosophila sensory organ precursor. Curr Biol 23: 581-587.

Couturier L, Mazouni K, Schweisguth F. 2013. Numb localizes at endosomes and controls the endosomal Sorting of Notch after asymmetric division in Drosophila. Curr Biol 23: $588-593$.

Cullen PJ. 2008. Endosomal sorting and signalling: An emerging role for sorting nexins. Nat Rev Mol Cell Biol 9: 574-582.

Davey NE, Van Roey K, Weatheritt RJ, Toedt G, Uyar B, Altenberg B, Budd A, Diella F, Dinkel H, Gibson TJ. 2012. Attributes of short linear motifs. Mol Biosyst 8: 268-281.

Davis CG, Lehrman MA, Russell DW, Anderson RG, Brown MS, Goldstein JL. 1986. The J.D. mutation in familial hypercholesterolemia: Amino acid substitution in cytoplasmic domain impedes internalization of LDL receptors. Cell 45: 15-24.

Dell'Angelica EC, Klumperman J, Stoorvogel W, Bonifacino JS. 1998. Association of the AP-3 adaptor complex with clathrin. Science 280: 431-434.

Dho SE, French MB, Woods SA, McGlade CJ. 1999. Characterization of four mammalian numb protein isoforms. Identification of cytoplasmic and membrane-associated variants of the phosphotyrosine binding domain. J Biol Chem 274: 33097-33104.

* Di Fiore PP, von Zastrow M. 2014. Endocytosis, signaling, and beyond. Cold Spring Harb Perspect Biol doi: 10.1101/ cshperspect.a016865.

Di Paolo G, De Camilli P. 2006. Phosphoinositides in cell regulation and membrane dynamics. Nature 443: 651657.

Diril MK, Wienisch M, Jung N, Klingauf J, Haucke V. 2006. Stonin 2 is an AP-2-dependent endocytic sorting adaptor for synaptotagmin internalization and recycling. $\mathrm{Dev}$ Cell 10: 233-244.

Donoso M, Cancino J, Lee J, van Kerkhof P, Retamal C, Bu G, Gonzalez A, Caceres A, Marzolo MP. 2009. Polarized traffic of LRP1 involves AP1B and SNX17 operating on Y-dependent sorting motifs in different pathways. $\mathrm{Mol}$ Biol Cell 20: 481-497. 
L.M. Traub and J.S. Bonifacino

Doray B, Lee I, Knisely J, Bu G, Kornfeld S. 2007. The $\gamma / \sigma 1$ and $\alpha / \sigma 2$ hemicomplexes of clathrin adaptors AP- 1 and AP-2 harbor the dileucine recognition site. Mol Biol Cell 18: 1887-1896.

Doray B, Knisely JM, Wartman L, Bu G, Kornfeld S 2008. Identification of acidic dileucine signals in LRP9 that interact with both GGAs and AP-1/AP-2. Traffic 9: 1551-1562.

Drake MT, Traub LM. 2001. Interaction of two structurally distinct sequence types with the clathrin terminal domain $\beta$-propeller. J Biol Chem 276: 28700-28709.

Dvir H, Shah M, Girardi E, Guo L, Farquhar MG, Zajonc DM. 2012. Atomic structure of the autosomal recessive hypercholesterolemia phosphotyrosine-binding domain in complex with the LDL-receptor tail. Proc Natl Acad Sci 10: 6916-6921.

Dwyer ND, Adler CE, Crump JG, L'Etoile ND, Bargmann CI. 2001. Polarized dendritic transport and the AP-1 $\mu 1$ clathrin adaptor UNC-101 localize odorant receptors to olfactory cilia. Neuron 31: 277-287.

Edeling MA, Mishra SK, Keyel PA, Steinhauser AL, Collins BM, Roth R, Heuser JE, Owen DJ, Traub LM. 2006. Molecular switches involving the AP-2 $\beta 2$ appendage regulate endocytic cargo selection and clathrin coat assembly. Dev Cell 10: 329-342.

Estes PS, Jackson TC, Stimson DT, Sanyal S, Kelly LE, Ramaswami M. 2003. Functional dissection of a eukaryotic dicistronic gene: Transgenic stonedB, but not stonedA, restores normal synaptic properties to Drosophila stoned mutants. Genetics 165: 185-196.

Eto DS, Gordon HB, Dhakal BK, Jones TA, Mulvey MA. 2008. Clathrin, AP-2, and the NPXY-binding subset of alternate endocytic adaptors facilitate FimH-mediated bacterial invasion of host cells. Cell Microbiol 10: 25532567.

Fang L, Garuti R, Kim BY, Wade JB, Welling PA. 2009. The ARH adaptor protein regulates endocytosis of the ROMK potassium secretory channel in mouse kidney. J Clin Invest 119: 3278-3289.

Farias GG, Cuitino L, Guo X, Ren X, Jarnik M, Mattera R, Bonifacino JS. 2012. Signal-mediated, AP-1/clathrin-dependent sorting of transmembrane receptors to the somatodendritic domain of hippocampal neurons. Neuron 75: $810-823$.

Farooq A, Zhou MM. 2004. PTB or not to be: Promiscuous, tolerant and bizarro domains come of age. IUBMB Life 56: $547-557$.

Fergestad T, Broadie K. 2001. Interaction of stoned and synaptotagmin in synaptic vesicle endocytosis. J Neurosci 21: $1218-1227$.

Ferguson SS, Downey WEr, Colapietro AM, Barak LS, Menard L, Caron MG. 1996. Role of $\beta$-arrestin in mediating agonist-promoted $\mathrm{G}$ protein-coupled receptor internalization. Science 271: 363-366.

Florian V, Schluter T, Bohnensack R. 2001. A new member of the sorting nexin family interacts with the $\mathrm{C}$-terminus of P-selectin. Biochem Biophys Res Commun 281: 10451050.

Folsch H, Ohno H, Bonifacino JS, Mellman I. 1999. A novel clathrin adaptor complex mediates basolateral targeting in polarized epithelial cells. Cell 99: 189-198.
Fujita Y, Nagaosa K, Shiratsuchi A, Nakanishi Y. 2012. Role of NPxY motif in Draper-mediated apoptotic cell clearance in Drosophila. Drug Discov Ther 6: 291-297.

Fukumatsu M, Ogawa M, Arakawa S, Suzuki M, Nakayama K, Shimizu S, Kim M, Mimuro H, Sasakawa C. 2012. Shigella targets epithelial tricellular junctions and uses a noncanonical clathrin-dependent endocytic pathway to spread between cells. Cell Host Microbe 11: 325-336.

Garcia CK, Wilund K, Arca M, Zuliani G, Fellin R, Maioli M, Calandra S, Bertolini S, Cossu F, Grishin N, et al. 2001. Autosomal recessive hypercholesterolemia caused by mutations in a putative LDL receptor adaptor protein. Science 292: 1394-1398.

Gephart JD, Singh B, Higginbotham JN, Franklin JL, Gonzalez A, Folsch H, Coffey RJ. 2011. Identification of a novel mono-leucine basolateral sorting motif within the cytoplasmic domain of amphiregulin. Traffic 12: 1793-1804.

Ghai R, Mobli M, Norwood SJ, Bugarcic A, Teasdale RD, King GF, Collins BM. 2011. Phox homology band 4.1/ ezrin/radixin/moesin-like proteins function as molecular scaffolds that interact with cargo receptors and Ras GTPases. Proc Natl Acad Sci 108: 7763-7768.

Ghai R, Bugarcic A, Liu H, Norwood SJ, Skeldal S, Coulson EJ, Li SS, Teasdale RD, Collins BM. 2013. Structural basis for endosomal trafficking of diverse transmembrane cargos by PX-FERM proteins. Proc Natl Acad Sci 110: E643-E652.

Goh LK, Huang F, Kim W, Gygi S, Sorkin A. 2010. Multiple mechanisms collectively regulate clathrin-mediated endocytosis of the epidermal growth factor receptor. J Cell Biol 189: 871-883.

Gonzalez C, Moss SJ, Olsen RW. 2012. Ethanol promotes clathrin adaptor-mediated endocytosis via the intracellular domain of $\delta$-containing GABAA receptors. J Neurosci 32: $17874-17881$.

Goodman OBJ, Krupnick JG, Santini F, Gurevich VV, Penn RB, Gagnon AW, Keen JH, Benovic JL. 1996. $\beta$-arrestin acts as a clathrin adaptor in endocytosis of the $\beta 2$-adrenergic receptor. Nature 383: 447-450.

Grzesiek S, Stahl SJ, Wingfield PT, Bax A. 1996. The CD4 determinant for downregulation by HIV-1 Nef directly binds to Nef. Mapping of the Nef binding surface by NMR. Biochemistry 35: 10256-10261.

Guo Y, Zanetti G, Schekman R. 2013. A novel GTP-binding protein-adaptor protein complex responsible for export of Vangl2 from the trans Golgi network. Elife 2: e00160.

Guttman M, Betts GN, Barnes H, Ghassemian M, van der Geer P, Komives EA. 2009. Interactions of the NPXY microdomains of the low density lipoprotein receptorrelated protein 1. Proteomics 9: 5016-5028.

He G, Gupta S, Yi M, Michaely P, Hobbs HH, Cohen JC. 2002. ARH is a modular adaptor protein that interacts with the LDL receptor, clathrin, and AP-2.J Biol Chem 277: 44044-44049.

Heldwein EE, Macia E, Wang J, Yin HL, Kirchhausen T, Harrison SC. 2004. Crystal structure of the clathrin adaptor protein 1 core. Proc Natl Acad Sci 101: 14108-14113.

Henne WM, Kent HM, Ford MG, Hegde BG, Daumke O, Butler PJ, Mittal R, Langen R, Evans PR, McMahon HT. 2007. Structure and analysis of FCHo2 F-BAR domain: A dimerizing and membrane recruitment module that effects membrane curvature. Structure 15: 839-852. 
Henne WM, Boucrot E, Meinecke M, Evergren E, Vallis Y, Mittal R, McMahon HT. 2010. FCHo proteins are nucleators of clathrin-mediated endocytosis. Science 328: $1281-1284$.

Hicke L, Riezman H. 1996. Ubiquitination of a yeast plasma membrane receptor signals its ligand-stimulated endocytosis. Cell 84: 277-287.

Hirst J, Barlow LD, Francisco GC, Sahlender DA, Seaman MN, Dacks JB, Robinson MS. 2011. The fifth adaptor protein complex. PLoS Biol 9: e1001170.

Hirst J, Borner GH, Antrobus R, Peden AA, Hodson NA, Sahlender DA, Robinson MS. 2012. Distinct and overlapping roles for AP-1 and GGAs revealed by the "knocksideways" system. Curr Biol 22: 1711-1716.

Holmes A, Flett A, Coudreuse D, Korswagen HC, Pettitt J. 2007. C. elegans disabled is required for cell-type specific endocytosis and is essential in animals lacking the AP-3 adaptor complex. J Cell Sci 120: 2741-2751.

Hong C, Duit S, Jalonen P, Out R, Scheer L, Sorrentino V, Boyadjian R, Rodenburg KW, Foley E, Korhonen L, et al. 2010. The E3 ubiquitin ligase IDOL induces the degradation of the low density lipoprotein receptor family members VLDLR and ApoER2. J Biol Chem 285: 1972019726.

Hornbeck PV, Chabra I, Kornhauser JM, Skrzypek E, Zhang B. 2004. PhosphoSite: A bioinformatics resource dedicated to physiological protein phosphorylation. Proteomics 4: 1551-1561.

Howard JP, Hutton JL, Olson JM, Payne GS. 2002. Sla1p serves as the targeting signal recognition factor for $\operatorname{NPFX}_{(1,2)} \mathrm{D}$-mediated endocytosis. J Cell Biol 157: $315-326$.

Huang F, Jiang X, Sorkin A. 2003. Tyrosine phosphorylation of the $\beta 2$ subunit of clathrin adaptor complex AP-2 reveals the role of a di-leucine motif in the epidermal growth factor receptor trafficking. J Biol Chem 278: 43411-43417.

Itoh T, De Camilli P. 2004. Membrane trafficking: Dual-key strategy. Nature 429: 141-143.

Jackson LP, Kelly BT, McCoy AJ, Gaffry T, James LC, Collins BM, Honing S, Evans PR, Owen DJ. 2010. A large-scale conformational change couples membrane recruitment to cargo binding in the AP2 clathrin adaptor complex. Cell 141: 1220-1229.

Jadot M, Canfield WM, Gregory W, Kornfeld S. 1992. Characterization of the signal for rapid internalization of the bovine mannose 6-phosphate/insulin-like growth factor-II receptor. J Biol Chem 267: 11069-11077.

Janvier K, Kato Y, Boehm M, Rose JR, Martina JA, Kim BY, Venkatesan S, Bonifacino JS. 2003. Recognition of dileucine-based sorting signals from HIV-1 Nef and LIMP-II by the AP- $1 \gamma-\sigma 1$ and AP- $3 \delta-\sigma 3$ hemicomplexes. J Cell Biol 163: 1281-1290.

Jha A, Watkins SC, Traub LM. 2102. The apoptotic engulfment protein Ced-6 participates in clathrin-mediated yolk uptake in Drosophila egg chambers. Mol Biol Cell 23: $1742-1764$.

Jia X, Singh R, Homann S, Yang H, Guatelli J, Xiong Y. 2012. Structural basis of evasion of cellular adaptive immunity by HIV-1 Nef. Nat Struct Mol Biol 19: 701-706.
Jin YJ, Cai CY, Zhang X, Zhang HT, Hirst JA, Burakoff SJ. 2005. HIV Nef-mediated CD4 down-regulation is adaptor protein complex 2 dependent. J Immunol 175: 3157-3164.

Jin YJ, Cai CY, Mezei M, Ohlmeyer M, Sanchez R, Burakoff SJ. 2012. Identification of a novel binding site between HIV Type 1 Nef C-terminal flexible loop and AP2 required for Nef-mediated CD4 downregulation. AIDS Res Hum Retroviruses 29: 725-731.

Johnson KF, Kornfeld S. 1992. The cytoplasmic tail of the mannose 6-phosphate/insulin-like growth factor-II receptor has two signals for lysosomal enzyme sorting in the Golgi. J Cell Biol 119: 249-257.

Jung N, Wienisch M, Gu M, Rand JB, Muller SL, Krause G, Jorgensen EM, Klingauf J, Haucke V. 2007. Molecular basis of synaptic vesicle cargo recognition by the endocytic sorting adaptor stonin 2. J Cell Biol 179: 1497-1510.

Kamikura DM, Cooper JA. 2003. Lipoprotein receptors and a disabled family cytoplasmic adaptor protein regulate EGL-17/FGF export in C. elegans. Genes Dev 17: $2798-$ 2811.

Kaneko T, Huang H, Cao X, Li X, Li C, Voss C, Sidhu SS, Li SS. 2012. Superbinder SH2 domains act as antagonists of cell signaling. Sci Signal 5: ra68.

Kang RS, Folsch H. 2011. ARH cooperates with AP-1B in the exocytosis of LDLR in polarized epithelial cells. J Cell Biol 193: 51-60.

Kang-Decker N, Mantchev GT, Juneja SC, McNiven MA, van Deursen JM. 2001. Lack of acrosome formation in Hrb-deficient mice. Science 294: 1531-1533.

Katoh M. 2004. Identification and characterization of human FCHO2 and mouse Fcho2 genes in silico. Int J Mol Med 14: 327-331.

Kelley LA, Sternberg MJ. 2009. Protein structure prediction on the Web: A case study using the Phyre server. Nat Protoc 4: 363-371.

Kelly BT, Owen DJ. 2011. Endocytic sorting of transmembrane protein cargo. Curr Opin Cell Biol 23: 404-412.

Kelly BT, McCoy AJ, Spate K, Miller SE, Evans PR, Honing S, Owen DJ. 2008. A structural explanation for the binding of endocytic dileucine motifs by the AP2 complex. $\mathrm{Na}$ ture 456: 976-979.

Kent HM, Evans PR, Schafer IB, Gray SR, Sanderson CM, Luzio JP, Peden AA, Owen DJ. 2012. Structural basis of the intracellular sorting of the SNARE VAMP7 by the AP3 adaptor complex. Dev Cell 22: 979-988.

Keyel PA, Thieman JR, Roth R, Erkan E, Everett ET, Watkins SC, Traub LM. 2008. The AP-2 adaptor b2 appendage scaffolds alternate cargo endocytosis. Mol Biol Cell 19: 5309-5326.

Kim SH, Ryan TA. 2009. Synaptic vesicle recycling at CNS synapses without AP-2. J Neurosci 29: 3865-3874.

* Kirchhausen T. 2014. Clathrin-mediated endocytosis. I: Structure and design of CCVs. Cold Spring Harb Perspect Biol doi: 10.1101/cshperspect.a016725.

Knauth P, Schluter T, Czubayko M, Kirsch C, Florian V, Schreckenberger S, Hahn H, Bohnensack R. 2005. Functions of sorting nexin 17 domains and recognition motif for P-selectin trafficking. J Mol Biol 347: 813-825.

Koh TW, Korolchuk VI, Wairkar YP, Jiao W, Evergren E, Pan H, Zhou Y, Venken KJ, Shupliakov O, Robinson IM, 
L.M. Traub and J.S. Bonifacino

et al. 2007. Eps15 and Dap160 control synaptic vesicle membrane retrieval and synapse development. J Cell Biol 178: $309-322$.

Kononenko NL, Diril MK, Puchkov D, Kintscher M, Koo SJ, Pfuhl G, Winter Y, Wienisch M, Klingauf J, Breustedt J, et al. 2013. Compromised fidelity of endocytic synaptic vesicle protein sorting in the absence of stonin 2. Proc Natl Acad Sci 110: E526-E535.

Koo SJ, Markovic S, Puchkov D, Mahrenholz CC, BecerenBraun F, Maritzen T, Dernedde J, Volkmer R, Oschkinat H, Haucke V. 2011. SNARE motif-mediated sorting of synaptobrevin by the endocytic adaptors clathrin assembly lymphoid myeloid leukemia (CALM) and AP180 at synapses. Proc Natl Acad Sci 108: 13540-13545.

Kozik P, Francis RW, Seaman MN, Robinson MS. 2010. A screen for endocytic motifs. Traffic 11: 843-855.

Krauss M, Kinuta M, Wenk MR, De Camilli P, Takei K, Haucke V. 2003. ARF6 stimulates clathrin/AP-2 recruitment to synaptic membranes by activating phosphatidylinositol phosphate kinase type I $\gamma$. J Cell Biol 162: 113124.

Krieger JR, Taylor P, Gajadhar AS, Guha A, Moran MF, McGlade CJ. 2012. Identification and SRM quantification of endocytosis factors associated with Numb. Mol Cell Proteomics 12: 499-514.

Ladbury JE, Arold ST. 2012. Noise in cellular signaling pathways: Causes and effects. Trends Biochem Sci 37: 173-178.

Lee I, Doray B, Govero J, Kornfeld S. 2008a. Binding of cargo sorting signals to AP-1 enhances its association with ADP ribosylation factor 1-GTP. J Cell Biol 180: 467-472.

Lee J, Retamal C, Cuitino L, Caruano-Yzermans A, Shin JE, van Kerkhof P, Marzolo MP, Bu G. 2008b. Adaptor protein sorting nexin 17 regulates amyloid precursor protein trafficking and processing in the early endosomes. J Biol Chem 283: 11501-11508.

Letourneur F, Klausner RD. 1992. A novel di-leucine motif and a tyrosine-based motif independently mediate lysosomal targeting and endocytosis of CD3 chains. Cell 69: $1143-1157$.

Li W, Puertollano-Moro R, Bonifacino J, Overbeek P, Everett E. 2010. Disruption of the murine $A p 2 \beta 1$ gene causes nonsyndromic cleft palate. Cleft Palate Craniofac J 47: $566-573$.

Lindwasser OW, Smith WJ, Chaudhuri R, Yang P, Hurley JH, Bonifacino JS. 2008. A diacidic motif in human immunodeficiency virus type $1 \mathrm{Nef}$ is a novel determinant of binding to AP-2. J Virol 82: 1166-1174.

Liu AP, Aguet F, Danuser G, Schmid SL. 2010. Local clustering of transferrin receptors promotes clathrin-coated pit initiation. J Cell Biol 191: 1381-1393.

Lubben NB, Sahlender DA, Motley AM, Lehner PJ, Benaroch P, Robinson MS. 2007. HIV-1 Nef-induced downregulation of MHC class I requires AP- 1 and clathrin but not PACS-1 and is impeded by AP-2. Mol Biol Cell 18: 3351-3365.

Mardones GA, Burgos PV, Lin Y, Kloer DP, Magadan JG, Hurley JH, Bonifacino JS. 2013. Structural basis for the recognition of tyrosine-based sorting signals by the $\mu 3 \mathrm{~A}$ subunit of the AP-3 adaptor complex. J Biol Chem 288: 9563-9571.
Margeta MA, Wang GJ, Shen K. 2009. Clathrin adaptor AP-1 complex excludes multiple postsynaptic receptors from axons in C. elegans. Proc Natl Acad Sci 106: 1632-1637.

Martina JA, Bonangelino CJ, Aguilar RC, Bonifacino JS. 2001. Stonin 2: An adaptor-like protein that interacts with components of the endocytic machinery. J Cell Biol 153: 1111-1120.

Mattera R, Boehm M, Chaudhuri R, Prabhu Y, Bonifacino JS. 2011. Conservation and diversification of dileucine signal recognition by adaptor protein (AP) complex variants. J Biol Chem 286: 2022-2030.

McGill MA, Dho SE, Weinmaster G, McGlade CJ. 2009. Numb regulates post-endocytic trafficking and degradation of Notch1. J Biol Chem 284: 26427-26438.

McMahon HT, Boucrot E. 2011. Molecular mechanism and physiological functions of clathrin-mediated endocytosis. Nat Rev Mol Cell Biol 12: 517-533.

Mettlen M, Loerke D, Yarar D, Danuser G, Schmid SL. 2010. Cargo- and adaptor-specific mechanisms regulate clathrin-mediated endocytosis. J Cell Biol 188: 919-933.

Miller SE, Sahlender DA, Graham SC, Honing S, Robinson MS, Peden AA, Owen DJ. 2011. The molecular basis for the endocytosis of small R-SNAREs by the clathrin adaptor CALM. Cell 147: 1118-1131.

Mishra SK, Keyel PA, Hawryluk MJ, Agostinelli NR, Watkins SC, Traub LM. 2002. Disabled-2 exhibits the properties of a cargo-selective endocytic clathrin adaptor. EMBO J 21: 4915-4926.

Mishra SK, Keyel PA, Edeling MA, Owen DJ, Traub LM. 2005. Functional dissection of an AP-2 $\beta 2$ appendagebinding sequence within the autosomal recessive hypercholesterolemia (ARH) protein. J Biol Chem 280: 19270 19280.

Moravcevic K, Oxley CL, Lemmon MA. 2012. Conditional peripheral membrane proteins: Facing up to limited specificity. Structure 20: 15-27.

Morris SM, Tallquist MD, Rock CO, Cooper JA. 2002. Dual roles for the Dab2 adaptor protein in embryonic development and kidney transport. EMBO J 21: 1555-1564.

Mulkearns EE, Cooper JA. 2012. FCHO2 organizes clathrincoated structures and interacts with Dab2 for LDLR endocytosis. Mol Biol Cell 23: 1330-1342.

Mullen GP, Grundahl KM, Gu M, Watanabe S, Hobson RJ, Crowell JA, McManus JR, Mathews EA, Jorgensen EM, Rand JB. 2012. UNC-41/Stonin functions with AP2 to recycle synaptic vesicles in Caenorhabditis elegans. PLoS ONE 7: e40095.

Mundell SJ, Luo J, Benovic JL, Conley PB, Poole AW. 2006. Distinct clathrin-coated pits sort different $G$ proteincoupled receptor cargo. Traffic 7: 1420-1431.

Mutch SA, Kensel-Hammes P, Gadd JC, Fujimoto BS, Allen RW, Schiro PG, Lorenz RM, Kuyper CL, Kuo JS, Bajjalieh $\mathrm{SM}$, et al. 2011. Protein quantification at the single vesicle level reveals that a subset of synaptic vesicle proteins are trafficked with high precision. J Neurosci 31: 1461-1470.

Nilsson L, Conradt B, Ruaud AF, Chen CC, Hatzold J, Bessereau JL, Grant BD, Tuck S. 2008. Caenorhabditis elegans num-1 negatively regulates endocytic recycling. Genetics 179: $375-387$. 
Nilsson L, Jonsson E, Tuck S. 2011. Caenorhabditis elegans numb inhibits endocytic recycling by binding TAT- 1 aminophospholipid translocase. Traffic 12: 1839-1849.

Ohno H, Stewart J, Fournier MC, Bosshart H, Rhee I, Miyatake S, Saito T, Gallusser A, Kirchhausen T, Bonifacino JS. 1995. Interaction of tyrosine-based sorting signals with clathrin-associated proteins. Science 269: 18721875.

Ohno H, Fournier MC, Poy G, Bonifacino JS. 1996. Structural determinants of interaction of tyrosine-based sorting signals with the adaptor medium chains. J Biol Chem 271: 29009-29015.

Ohno H, Aguilar RC, Yeh D, Taura D, Saito T, Bonifacino JS. 1998. The medium subunits of adaptor complexes recognize distinct but overlapping sets of tyrosine-based sorting signals. J Biol Chem 273: 25915-25921.

Olusanya O, Andrews PD, Swedlow JR, Smythe E. 2001. Phosphorylation of threonine 156 of the $\mu 2$ subunit of the AP2 complex is essential for endocytosis in vitro and in vivo. Curr Biol 11: 896-900.

Ortega B, Mason AK, Welling PA. 2012. A tandem di-hydrophobic motif mediates clathrin-dependent endocytosis via direct binding to the AP- $2 \alpha \sigma 2$ subunits. J Biol Chem 287: 26867-26875.

Owen DJ, Evans PR. 1998. A structural explanation for the recognition of tyrosine-based endocytotic signals. Science 282: 1327-1332.

Owen DJ, Setiadi H, Evans PR, McEver RP, Green SA. 2001. A third specificity-determining site in $\mu 2$ adaptin for sequences upstream of $\mathrm{Yxx} \Phi$ sorting motifs. Traffic 2: $105-110$.

Paleotti O, Macia E, Luton F, Klein S, Partisani M, Chardin P, Kirchhausen T, Franco M. 2005. The small G-protein Arf6GTP recruits the AP-2 adaptor complex to membranes. J Biol Chem 280: 21661-21666.

Pearson MA, Reczek D, Bretscher A, Karplus PA. 2000. Structure of the ERM protein moesin reveals the FERM domain fold masked by an extended actin binding tail domain. Cell 101: 259-270.

Pedersen GA, Chakraborty S, Steinhauser AL, Traub LM, Madsen M. 2010. AMN directs endocytosis of the intrinsic factor-vitamin $B_{12}$ receptor cubam by engaging ARH or Dab2. Traffic 11: 706-720.

* Piper RC, Dikic I, Lukacs G. 2014. Ubiquitin-dependent sorting in endocytosis. Cold Spring Harb Perspect Biol doi: $10.1101 /$ cshperspect.a016808.

Pitcher C, Honing S, Fingerhut A, Bowers K, Marsh M. 1999. Cluster of differentiation antigen 4 (CD4) endocytosis and adaptor complex binding require activation of the CD4 endocytosis signal by serine phosphorylation. Mol Biol Cell 10: 677-691.

Polo S, Sigismund S, Faretta M, Guidi M, Capua MR, Bossi G, Chen H, De Camilli P, Di Fiore PP. 2002. A single motif responsible for ubiquitin recognition and monoubiquitination in endocytic proteins. Nature 416: 451455.

Pond L, Kuhn LA, Teyton L, Schutze MP, Tainer JA, Jackson MR, Peterson PA. 1995. A role for acidic residues in dileucine motif-based targeting to the endocytic pathway. J Biol Chem 270: 19989-19997.
Pozzi B, Amodio S, Lucano C, Sciullo A, Ronzoni S, Castelletti D, Adler T, Treise I, Betsholtz IH, Rathkolb B, et al. 2012. The endocytic adaptor eps15 controls marginal zone B cell numbers. PLoS ONE 7: e50818.

Prabhu Y, Burgos PV, Schindler C, Farias GG, Magadan JG, Bonifacino JS. 2012. Adaptor protein 2-mediated endocytosis of the $\beta$-secretase BACE1 is dispensable for amyloid precursor protein processing. Mol Biol Cell 23: 2339-2351.

Pryor PR, Jackson L, Gray SR, Edeling MA, Thompson A, Sanderson CM, Evans PR, Owen DJ, Luzio JP. 2008. Molecular basis for the sorting of the SNARE VAMP7 into endocytic clathrin-coated vesicles by the ArfGAP Hrb. Cell 134: 817-827.

Puthenveedu MA, von Zastrow M. 2006. Cargo regulates clathrin-coated pit dynamics. Cell 127: 113-124.

Reider A, Wendland B. 2011. Endocytic adaptors-Social networking at the plasma membrane. J Cell Sci 124: 1613-1622.

Reider A, Barker SL, Mishra SK, Im YJ, Maldonado-Baez L, Hurley JH, Traub LM, Wendland B. 2009. Syp1 is a conserved endocytic adaptor that contains domains involved in cargo selection and membrane tubulation. $E M B O$ J 28: 3103-3116.

Ren X, Farias GG, Canagarajah BJ, Bonifacino JS, Hurley JH. 2013. Structural basis for recruitment and activation of the AP-1 clathrin adaptor complex by Arf1. Cell 152: $755-767$.

Ricotta D, Conner SD, Schmid SL, von Figura K, Honing S. 2002. Phosphorylation of the AP2 mu subunit by AAK1 mediates high affinity binding to membrane protein sorting signals. J Cell Biol 156: 791-795.

Robinson MS. 2004. Adaptable adaptors for coated vesicles. Trends Cell Biol 14: 167-174.

Roeth JF, Williams M, Kasper MR, Filzen TM, Collins KL. 2004. HIV-1 Nef disrupts MHC-I trafficking by recruiting AP-1 to the MHC-I cytoplasmic tail. J Cell Biol 167: 903-913.

Rohrer J, Schweizer A, Russell D, Kornfeld S. 1996. The targeting of Lamp1 to lysosomes is dependent on the spacing of its cytoplasmic tail tyrosine sorting motif relative to the membrane. J Cell Biol 132: 565-576.

Royle SJ, Qureshi OS, Bobanovic LK, Evans PR, Owen DJ, Murrell-Lagnado RD. 2005. Non-canonical YXXGF endocytic motifs: Recognition by AP2 and preferential utilization in P2X4 receptors. J Cell Sci 118: $3073-$ 3080.

Schmid EM, Ford MG, Burtey A, Praefcke GJ, Peak Chew SY, Mills IG, Benmerah A, McMahon HT. 2006. Role of the AP2 $\beta$-appendage hub in recruiting partners for clathrin coated vesicle assembly. PLoS Biol 4: e262.

Schweizer A, Kornfeld S, Rohrer J. 1996. Cysteine34 of the cytoplasmic tail of the cation-dependent mannose 6-phosphate receptor is reversibly palmitoylated and required for normal trafficking and lysosomal enzyme sorting. J Cell Biol 132: 577-584.

Scotland PB, Heath JL, Conway AE, Porter NB, Armstrong MB, Walker JA, Klebig ML, Lavau CP, Wechsler DS. 2012. The PICALM protein plays a key role in iron homeostasis and cell proliferation. PLOS ONE 7: e44252. 
L.M. Traub and J.S. Bonifacino

Scotti E, Calamai M, Goulbourne CN, Zhang L, Hong C, Lin RR, Choi J, Pilch PF, Fong LG, Zou P, et al. 2013. IDOL stimulates clathrin-independent endocytosis and MVBmediated lysosomal degradation of the LDLR. Mol Cell Biol 33: 1503-1514.

Selbach M, Paul FE, Brandt S, Guye P, Daumke O, Backert S, Dehio C, Mann M. 2009. Host cell interactome of tyrosine-phosphorylated bacterial proteins. Cell Host Microbe 5: 397-403.

Shih SC, Katzmann DJ, Schnell JD, Sutanto M, Emr SD, Hicke L. 2002. Epsins and Vps27p/Hrs contain ubiquitin-binding domains that function in receptor endocytosis. Nat Cell Biol 4: 389-393.

Shiratori T, Miyatake S, Ohno H, Nakaseko C, Isono K, Bonifacino JS, Saito T. 1997. Tyrosine phosphorylation controls internalization of CTLA-4 by regulating its interaction with clathrin-associated adaptor complex AP-2. Immunity 6: 583-589.

Smith CA, Dho SE, Donaldson J, Tepass U, McGlade CJ. 2004. The cell fate determinant numb interacts with EHD/Rme-1 family proteins and has a role in endocytic recycling. Mol Biol Cell 15: 3698-3708.

Smith CA, Lau KM, Rahmani Z, Dho SE, Brothers G, She YM, Berry DM, Bonneil E, Thibault P, Schweisguth F, et al. 2007. aPKC-mediated phosphorylation regulates asymmetric membrane localization of the cell fate determinant Numb. ЕMBO J 26: 468-480.

Sorensen EB, Conner SD. 2008. AAK1 regulates numb function at an early step in clathrin-mediated endocytosis. Traffic 9: 1791-1800.

Sorrentino V, Scheer L, Santos A, Reits E, Bleijlevens B, Zelcer N. 2011. Distinct functional domains contribute to degradation of the low density lipoprotein receptor (LDLR) by the E3 ubiquitin ligase inducible Degrader of the LDLR (IDOL). J Biol Chem 286: 30190-30199.

Stamnes MA, Rothman JE. 1993. The binding of AP-1 clathrin adaptor particles to Golgi membranes requires ADP-ribosylation factor, a small GTP-binding protein. Cell 73: 999-1005.

Steinberg F, Heesom KJ, Bass MD, Cullen PJ. 2012. SNX17 protects integrins from degradation by sorting between lysosomal and recycling pathways. J Cell Biol 197: 219230.

Stimson DT, Estes PS, Rao S, Krishnan KS, Kelly LE, Ramaswami M. 2001. Drosophila stoned proteins regulate the rate and fidelity of synaptic vesicle internalization. J Neurosci 21: 3034-3044.

Stockinger W, Sailler B, Strasser V, Recheis B, Fasching D, Kahr L, Schneider WJ, Nimpf J. 2002. The PX-domain protein SNX17 interacts with members of the LDL receptor family and modulates endocytosis of the LDL receptor. EMBO J 21: 4259-4267.

Suzuki M, Tanaka H, Tanimura A, Tanabe K, Oe N, Rai S, Kon S, Fukumoto M, Takei K, Abe T, et al. 2012. The clathrin assembly protein PICALM is required for erythroid maturation and transferrin internalization in mice. PLoS ONE 7: e31854.

Takamori S, Holt M, Stenius K, Lemke EA, Gronborg M, Riedel D, Urlaub H, Schenck S, Brugger B, Ringler P, et al. 2006. Molecular anatomy of a trafficking organelle. Cell 127: 831-846.
Tan PK, Howard JP, Payne GS. 1996. The sequence NPFXD defines a new class of endocytosis signal in Saccharomyces cerevisiae. J Cell Biol 135: 1789-1800.

Teasdale RD, Collins BM. 2012. Insights into the PX (phoxhomology) domain and SNX (sorting nexin) protein families: Structures, functions and roles in disease. Biochem J 441: 39-59.

Tokarev A, Guatelli J. 2011. Misdirection of membrane trafficking by HIV-1 Vpu and Nef: Keys to viral virulence and persistence. Cell Logist 1: 90-102.

Tong X, Zitserman D, Serebriiskii I, Andrake M, Dunbrack R, Roegiers F. 2010. Numb independently antagonizes Sanpodo membrane targeting and Notch signaling in Drosophila sensory organ precursor cells. Mol Biol Cell 21: $802-810$.

Traub LM. 2009. Tickets to ride: Selecting cargo for clathrinregulated internalization. Nat Rev Mol Cell Biol 10: 583596.

Traub LM, Ostrom JA, Kornfeld S. 1993. Biochemical dissection of AP-1 recruitment onto Golgi membranes. J Cell Biol 123: 561-573.

Tsushima H, Malabarba MG, Confalonieri S, Senic-Matuglia F, Verhoef LG, Bartocci C, D’Ario G, Cocito A, Di Fiore PP, Salcini AE. 2013. A snapshot of the physical and functional wiring of the eps15 homology domain network in the nematode. PLoS ONE 8: e56383.

Uhlik MT, Temple B, Bencharit S, Kimple AJ, Siderovski DP, Johnson GL. 2005. Structural and evolutionary division of phosphotyrosine binding (PTB) domains. J Mol Biol 345: $1-20$.

Umasankar PK, Sanker S, Thieman JR, Chakraborty S, Wendland B, Tsang M, Traub LM. 2012. Distinct and separable activities of the endocytic clathrin-coat components Fchol $/ 2$ and AP-2 in developmental patterning. Nat Cell Biol 14: 488-501.

van Kerkhof P, Lee J, McCormick L, Tetrault E, Lu W, Schoenfish M, Oorschot V, Strous GJ, Klumperman J, Bu G. 2005. Sorting nexin 17 facilitates LRP recycling in the early endosome. EMBO J 24: 2851-2861.

Voorhees P, Deignan E, van Donselaar E, Humphrey J, Marks MS, Peters PJ, Bonifacino JS. 1995. An acidic sequence within the cytoplasmic domain of furin functions as a determinant of trans-Golgi network localization and internalization from the cell surface. EMBO J 14: 49614975.

Walther K, Krauss M, Diril MK, Lemke S, Ricotta D, Honing S, Kaiser S, Haucke V. 2001. Human stoned B interacts with AP-2 and synaptotagmin and facilitates clathrincoated vesicle uncoating. EMBO Rep 2: 634-640.

Wang YJ, Wang J, Sun HQ, Martinez M, Sun YX, Macia E, Kirchhausen T, Albanesi JP, Roth MG, Yin HL. 2003. Phosphatidylinositol 4 phosphate regulates targeting of clathrin adaptor AP-1 complexes to the Golgi. Cell 114: 299-310.

Wang W, Bouhours M, Gracheva EO, Liao EH, Xu K, Sengar AS, Xin X, Roder J, Boone C, Richmond JE, et al. 2008. ITSN-1 controls vesicle recycling at the neuromuscular junction and functions in parallel with DAB-1. Traffic 9: 742-754.

Wang Z, Sandiford S, Wu C, Li SS. 2009. Numb regulates cell-cell adhesion and polarity in response to tyrosine kinase signalling. $E M B O J$ 28: 2360-2373. 
Cargo Recognition in Clathrin-Mediated Endocytosis

Wang CC, Sato K, Otsuka Y, Otsu W, Inaba M. 2012. Clathrin-mediated endocytosis of mammalian erythroid AE1 anion exchanger facilitated by a YXX $\Phi$ or a noncanonical YXXX $\Phi$ motif in the N-terminal stretch. $J$ Vet Med Sci 74: 17-25.

Warren RA, Green FA, Stenberg PE, Enns CA. 1998. Distinct saturable pathways for the endocytosis of different tyrosine motifs. J Biol Chem 273: 17056-17063.

Wegener KL, Partridge AW, Han J, Pickford AR, Liddington RC, Ginsberg MH, Campbell ID. 2007. Structural basis of integrin activation by talin. Cell 128: 171-182.
Willox AK, Royle SJ. 2012. Stonin 2 is a major adaptor protein for clathrin-mediated synaptic vesicle retrieval. Curr Biol 22: 1435-1439.

Yu A, Xing Y, Harrison SC, Kirchhausen T. 2010. Structural analysis of the interaction between Dishevelled2 and clathrin AP-2 adaptor, a critical step in noncanonical Wnt signaling. Structure 18: 1311-1320.

Zelcer N, Hong C, Boyadjian R, Tontonoz P. 2009. LXR regulates cholesterol uptake through Idol-dependent ubiquitination of the LDL receptor. Science 325: $100-$ 104. 


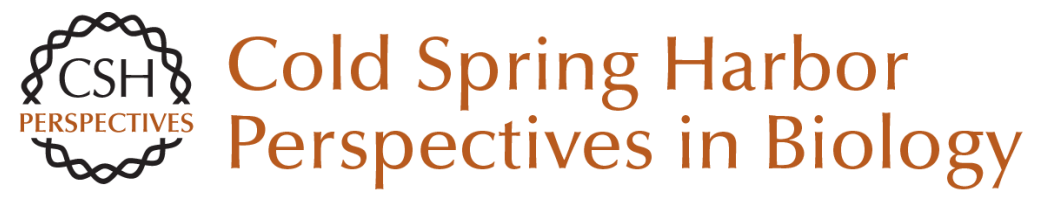

\section{Cargo Recognition in Clathrin-Mediated Endocytosis}

Linton M. Traub and Juan S. Bonifacino

Cold Spring Harb Perspect Biol 2013; doi: 10.1101/cshperspect.a016790

Subject Collection Endocytosis

\section{Endocytosis: Past, Present, and Future} Sandra L. Schmid, Alexander Sorkin and Marino Zerial

Rab Proteins and the Compartmentalization of the Endosomal System

Angela Wandinger-Ness and Marino Zerial

Cargo Sorting in the Endocytic Pathway: A Key Regulator of Cell Polarity and Tissue Dynamics Suzanne Eaton and Fernando Martin-Belmonte

Unconventional Functions for Clathrin, ESCRTs, and Other Endocytic Regulators in the

Cytoskeleton, Cell Cycle, Nucleus, and Beyond:

Links to Human Disease

Frances M. Brodsky, R. Thomas Sosa, Joel A. Ybe, et al.

Endocytosis of Viruses and Bacteria Pascale Cossart and Ari Helenius

Lysosomal Adaptation: How the Lysosome

Responds to External Cues Carmine Settembre and Andrea Ballabio

Reciprocal Regulation of Endocytosis and Metabolism

Costin N. Antonescu, Timothy E. McGraw and Amira Klip

Endocytosis and Autophagy: Exploitation or Cooperation?

Sharon A. Tooze, Adi Abada and Zvulun Elazar
Imaging and Modeling the Dynamics of

Clathrin-Mediated Endocytosis

Marcel Mettlen and Gaudenz Danuser

Endocytic Accessory Factors and Regulation of

Clathrin-Mediated Endocytosis

Christien J. Merrifield and Marko Kaksonen

The Complex Ultrastructure of the Endolysosomal

System Judith Klumperman and Graça Raposo

The Biogenesis of Lysosomes and

Lysosome-Related Organelles J. Paul Luzio, Yvonne Hackmann, Nele M.G. Dieckmann, et al.

Endocytosis, Signaling, and Beyond Pier Paolo Di Fiore and Mark von Zastrow

Clathrin-Independent Pathways of Endocytosis Satyajit Mayor, Robert G. Parton and Julie G. Donaldson

The Role of Endocytosis during Morphogenetic Signaling Marcos Gonzalez-Gaitan and Frank Jülicher

Role of Endosomes and Lysosomes in Human Disease

Frederick R. Maxfield

For additional articles in this collection, see http://cshperspectives.cshlp.org/cgi/collection/

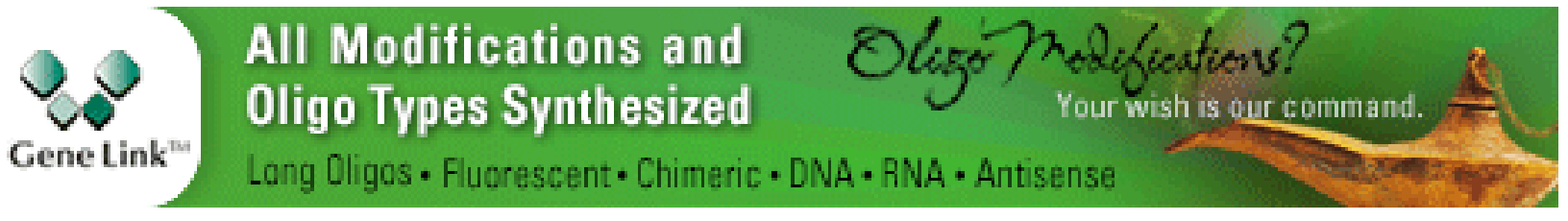


For additional articles in this collection, see http://cshperspectives.cshlp.org/cgi/collection/

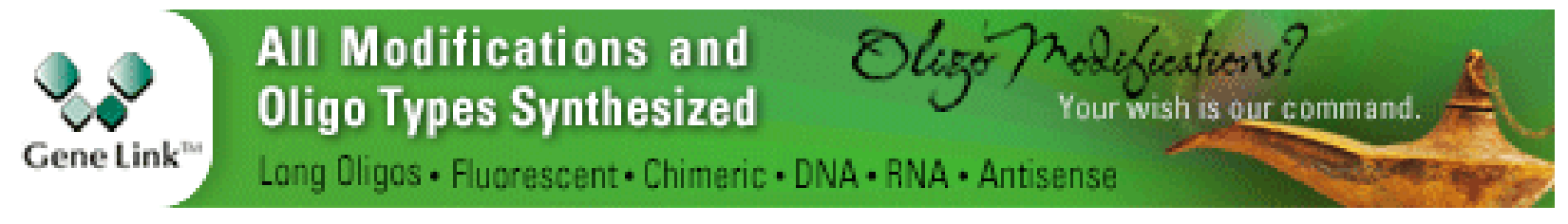

Copyright @ 2013 Cold Spring Harbor Laboratory Press; all rights reserved 